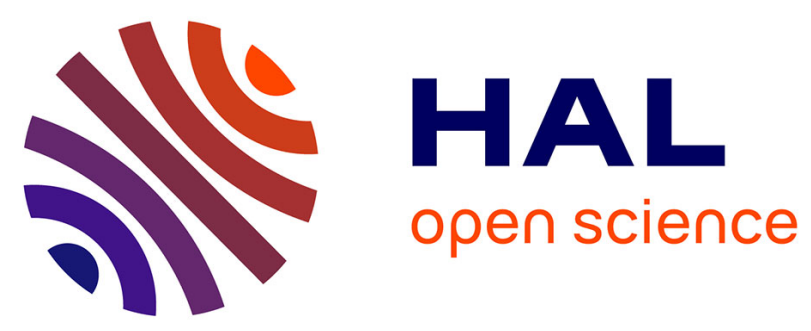

\title{
Dealing with shallow groundwater contexts for the modelling of urban hydrology - A simplified approach to represent interactions between surface hydrology, groundwater and underground structures in hydrological models
}

William Pophillat, Jérémie Sage, Fabrice Rodriguez, Isabelle Braud

\section{To cite this version:}

William Pophillat, Jérémie Sage, Fabrice Rodriguez, Isabelle Braud. Dealing with shallow groundwater contexts for the modelling of urban hydrology - A simplified approach to represent interactions between surface hydrology, groundwater and underground structures in hydrological models. Environmental Modelling and Software, 2021, 144, pp.105144. 10.1016/j.envsoft.2021.105144 . hal-03322676

\section{HAL Id: hal-03322676 \\ https://hal.science/hal-03322676}

Submitted on 19 Aug 2021

HAL is a multi-disciplinary open access archive for the deposit and dissemination of scientific research documents, whether they are published or not. The documents may come from teaching and research institutions in France or abroad, or from public or private research centers.
L'archive ouverte pluridisciplinaire HAL, est destinée au dépôt et à la diffusion de documents scientifiques de niveau recherche, publiés ou non, émanant des établissements d'enseignement et de recherche français ou étrangers, des laboratoires publics ou privés.

\section{(ㅇ)(1) $\$$}

Distributed under a Creative Commons Attribution - NonCommercial - NoDerivatives $\mid 4.0$ 
William Pophillat, Jérémie Sage, Fabrice Rodriguez, Isabelle Braud (2021), Dealing with shallow groundwater contexts for the modelling of urban hydrology - A simplified approach to represent interactions between surface hydrology, groundwater and underground structures in hydrological models, Environmental Modelling and Software, Volume 144, 105144,

The final publication is available via ScienceDirect at: https://doi.org/10.1016/j.envsoft.2021.105144.

(C) 2021. This manuscript version is made available under the CC-BY-NC-ND 4.0 license https://creativecommons.org/licenses/by-nc-nd/4.0/ 


\title{
Dealing with shallow groundwater contexts for the modelling of urban hydrology - A simplified approach to represent interactions between surface hydrology, groundwater and underground structures in hydrological models
}

\author{
William Pophillat a ${ }^{\text {a b, * }}$, Jérémie Sage ${ }^{\mathrm{a}}$, Fabrice Rodriguez ${ }^{\mathrm{c}}$, Isabelle Braud ${ }^{\mathrm{b}}$ \\ ${ }^{a}$ Cerema, Equipe-projet TEAM, 12 Rue Léon Teisserenc de Bort, 78190 Trappes, France; \\ b INRAE, RiverLy, 5 Rue de la Doua, CS 20244, 69625 Villeurbanne, France; \\ ${ }^{c}$ GERS-LEE, Univ Gustave Eiffel, IFSTTAR, Allée des Ponts et Chaussées CS 500444343 Bouguenais, France; \\ * corresponding author: william.pophillat@cerema.fr
}

\begin{abstract}
Hydrological modelling can be a relevant tool to support sustainable planning decisions. However, urban hydrological models usually rely on simplified underground representation that may limit their applicability in shallow groundwater environments. This paper introduces a set of modules designed to describe the numerous interactions between subsurface processes and surface hydrology that may occur in such contexts. The modules provide a rather straightforward approach to simulate the influence of the groundwater on the surface as well as the influence of several underground structures (sewer systems, building basements, ...) on subsurface storage and the volumes to be managed by the sewerage network. The modules are evaluated by comparison with reference models over a set of theoretical test cases and integrated within the URBS hydrological model. An application to a realistic hypothetical watershed is carried out to illustrate the benefits and the feasibility of these focussed development in existing urban hydrological models.
\end{abstract}

\section{Keywords}

Hydrological modelling; Urban hydrology; Urban hydrogeology; Hydrological processes; Groundwater; Unsaturated zone.

\section{Software availability}

Software name: URBS

Development team: Floriane Morena, Fabrice Rodriguez, Marie Laure Mosini, Yinghao Li, Jérémie Sage, William Pophillat

Availability: Free download at: http://doi.org/10.5281/zenodo.5115863

Program language: $\mathrm{C}$

Program size: 600 Ko

The model diagnosis was carried out using the following software packages:

- FEFLOW V7.2

- HYDRUS 1D V4.17

\section{List of notations}


Shape parameter of the Brooks and Corey' law in reservoir $k$

Distance between the centre of gravity of cell $i$ and the centre of the interface between cells $i$ and $j$

Root density in reservoir $k$

Ed

Evaporative demand

\section{Cumulative infiltration}


$\mathrm{BC}$

$\mathrm{CF}$

GW

SZ

$\mathrm{UZ}$

\section{Introduction}

About half of the world's population currently lives in urban areas. By 2050, these areas will be home to an additional 2.5 billion people, bringing together two-thirds of the world's population (United Nations, 2014). Urban expansion associated with such development implies significant changes in the hydrology of the affected watersheds. The sealing of natural surfaces leads to an increase in runoff volumes and to a decrease in stormwater volumes infiltrating into the soil, returning to the atmosphere trough evapotranspiration and contributing to groundwater $(\mathrm{GW})$ recharge (Fletcher et al., 2013). Combined with the rapid transfer of runoff volumes across urban surfaces and drainage network, it results in increased peak flows and volumes and shorter times of concentration (Fletcher et al., 2013). To mitigate these effects, stormwater management increasingly relies on small infiltration devices disseminated throughout urban catchments. However, the spatial concentration of runoff in such systems is likely to promote deep infiltration rather than evapotranspiration and thus to over-recharge GW (Göbel et al., 2004). Stormwater infiltration may also be associated with highly heterogeneous GW elevation with localized mounding beneath infiltration devices following rain events (Bhaskar et al., 2018). Overall consequences of urbanization on GW levels and base flow depend on a complex water budget. The balance involves a variety of sources, that not only include rainfall infiltration but also other anthropogenic sources such as network leakage or irrigation, and sinks such as drainage or pumping (Bhaskar et al., 2016). Besides, underground water pathways, local GW levels and GW flow systems are largely affected by the various soil modifications (e.g. backfill, compaction) and underground structures (e.g. sewer pipes, underground car parks, tunnels, equipped or not with drainage system) (Attard et al., 2016a).

These numerous disturbances make urbanized areas highly heterogeneous environments concentrating a wide variety of natural and anthropogenic processes interacting with each other at various spatio-temporal scales (Salvadore et al., 2015). These interactions are often challenging to quantify and greatly increase the complexity of the hydrological functioning of these systems. This is notably the case for interactions linking surface and underground processes. For instance, mounding forming beneath infiltration devices may increase transpiration in surrounding areas (Bonneau et al., 2018) or affect in turn the infiltration capacity within the devices (Bouwer, 2002). The rise in the water table resulting from the infiltration may also increase GW volumes drained by underground structures (e.g. GW seepage into sewer pipes (Kidmose et al., 2015)) which affects both water volumes to be managed by sewerage systems and subsurface water storage. The influence of such interactions on the hydrological functioning of the watershed depends strongly on the characteristics of the urban, hydrogeological and climatic contexts. In particular, shallow GW contexts (less than a few meters deep) have a high potential for significant interactions between surface and subsurface.

Understanding and managing the water cycle in urbanized areas in shallow GW contexts therefore requires hydrological models capable of taking these various processes and interactions into account (Hamel and Fletcher, 2014). Such models should be suited to the morphology of urban environments and to their specific components. They should simulate natural and urban processes involved (e.g. runoff generation over natural and impervious surfaces, evapotranspiration, unsaturated flows, GW interactions with underground structures). They should also take 
into account the various interactions between these processes (Salvadore et al., 2015) and the complex water paths in these environments (e.g. centralised/decentralised runoff management, fate of drained groundwater). They should allow long-term continuous simulations with rather high temporal resolution (a few minutes or less) (Salvadore et al., 2015). Finally, the computation times should not preclude the use of optimization procedures, sensitivity studies or multi-model scenarios to take into account the strong uncertainties regarding the underground composition.

Only a few hydrological models designed for urban environments integrate a representation of both the surface and underground compartments in their source code (e.g. SWMM (Rossman, 2016), WEP (Jia et al., 2001), URBS (Rodriguez et al., 2008)). These models usually incorporate a relatively fine representation of the urban environment and hydrological processes on the surface and a simplified description of the underground compartment. In usual modelling contexts, such descriptions provide satisfactory estimates of the influence of the underground compartment on the surface hydrology and of the impacts on subsurface storages and base flows. However, they neglect various processes and interactions that may significantly affect the water cycle in presence of a shallow water table and therefore limits the applicability of these models in such contexts. For instance, oversimplified representations of the unsaturated zone regarding soil heterogeneity, water content profile, and vertical fluxes (e.g. through single-reservoir approaches in URBS and SWMM) and non-consideration of capillary rise from the water table (e.g. in WEP, SWMM) limit the ability to represent the GW influence on evapotranspiration and surface infiltration and the GW recharge. Furthermore, conceptual GW flow calculations (e.g. in SWMM or URBS) are not appropriate to represent local fluctuations (e.g. mounding beneath infiltration structures) and their influence on surface. Besides, the use of squaremesh based GW flow computations (WEP) doesn't suit well to urban object geometry. Finally, interactions between GW and underground structures are usually neglected (except for GW seepage into sewer pipes in URBS and pumping in WEP) which hinders the consideration of their influence on subsurface water storage and on water volumes to be managed by sewer systems. The use of these models in shallow GW contexts therefore requires adaptations of the description of the subsurface compartment to better take into account the specificities of such environments.

A possible approach to overcome the limitations of these urban hydrology models is to couple them with GW models (e.g. FEFLOW, MODFLOW) or integrated hydrogeological models developed for natural environments (e.g. MIKESHE, GSFLOW). If such couplings are commonly described in the literature, many of them have not been designed to improve the representation of surface-subsurface interactions and rather focus on GW flows. As a consequence, only a few of them actually consist in "two-ways" couplings where feedbacks between surface and subsurface compartments are taken into account. Two-way couplings (e.g. SWMM-MODFLOW (Zhang and Chui, 2020), MIKE URBAN-MIKE SHE (Kidmose et al., 2015; Locatelli et al., 2017)) have the potential to simulate the urban water cycle in shallow GW contexts. Their use or implementation is however not necessarily straightforward. Two-way couplings may first be associated with a significant increase of computation time, limiting their applicability for optimization or sensitivity analysis procedures (Kidmose et al., 2015). They may also be difficult to set up as they involve dynamic exchanges between numerous calculation variables. In addition, the models used to describe the subsurface compartment may not provide pragmatic alternatives to overcome the limitations regarding the description of the unsaturated zone in urban hydrology models. The resolution of Richards equation, available in some models 
as the highest accuracy option, can become cumbersome in many applications (Zha et al., 2019). While simpler approaches (such as the kinematic wave solutions included in MODFLOW or GSFLOW) are also provided, they do not take into account diffusive fluxes or vertical soil heterogeneity. Besides, except MIKE SHE-MIKE URBAN, existing couplings do not consider interactions between GW and underground structures. Although their representation is possible with most of the models used to depict the subsurface compartment, their integration in couplings would require additional developments. Finally, if several groundwater models allow the use of irregular meshes (e.g. MODFLOW 6, MODFLOW-USG, FEFLOW), many others are based on rectangular meshes (e.g. other versions of MODFLOW, GSFLOW, MIKE-SHE) less adapted to the geometry of urban objects and the use of local refinements. The features of existing software or couplings are therefore not fully in line with the objectives commonly associated with urban hydrology models in shallow GW contexts. Instead, the introduction of selective developments in these models may also be a relevant approach to extend their applicability while taking advantage of their existing functionalities and retaining their relative simplicity.

In this study, a set of modules is introduced to describe the role of the urban underground compartment in shallow GW environments and integrated within the URBS model. The modules rely on a physically-based but relatively simple depiction of this compartment and its interactions with the surface. Given the simplifications involved, particular attention is paid to the evaluation of the modules ability to reproduce the processes and interactions of interest. Their integration into the URBS model aims to exploit the capabilities of an existing tool to develop a flexible modelling framework for the evaluation of the impacts of stormwater management strategies or urban developments on the water cycle in a variety of contexts, including shallow GW environments. This tool i) is suited to the complexity of urban landscapes and the geometry of their components ii) is able to simulate the evolution of the various terms of the water balance, the surface and subsurface storage and the complex water pathways in these environments (decentralized/centralized management of runoff, subsurface fate of infiltrated water, fate of drained groundwater or groundwater resurgence, etc. ) and iii) can be used to perform continuous simulations over long periods with computation times enabling optimization or sensitivity analysis procedures to be implemented.

The first section of the paper details the theoretical basis of the subsurface modelling approach. It is based on 1) a 2D GW flow computation module adapted to irregular meshes and allowing interactions with several underground structures to be taken into account (sewer systems, wells, underground constructions with or without draining systems) and 2) a reservoir model for the computation of vertical UZ flows capable of taking into account layered soils, vegetation transpiration and upward capillary rise from the water table. Section 2 of the paper details the diagnosis conducted to better understand the functioning and limitations of these modules regarding the processes and interactions of interest. It is based on comparisons with reference models (HYDRUS 1D (Šimůnek et al., 2005) and FEFLOW (Diersch, 2014)) over a set of hypothetical test cases. Section 3 introduces the integration of these modules into the URBS model. It also presents an application to a hypothetical yet realistic watershed designed to illustrate the model's applicability and potential benefits of considering such processes and interactions in shallow GW environments with stormwater infiltration devices. Finally, section 4 discusses the benefits and limits of the approach.

\section{Theoretical basis of the new modules}


This section details the theoretical basis of the modules developed to represent the urban underground compartment. The first sub-section describes the computation of GW flows and interactions with underground structures. The second sub-section focuses on the UZ flows computation. Finally, the last sub-section details the computation procedure.

\subsection{Saturated zone}

\subsubsection{Lateral groundwater flows}

The modelling of GW flow is based on a 2D application of Darcy's law at the interfaces between computation cells (Eq. 1, Figure1). The computation is done by sequentially estimating the flow at each interface, on the basis of hydraulic heads at the previous time step.

$$
V_{i j}=-\vec{\nabla} H \cdot \vec{n} T_{i j} L_{i j} \Delta t
$$

Where $V_{i j}\left[\mathrm{~m}^{3}\right]$ is the volume exchanged between cells $i$ and $j$ during a time step $\Delta t, \vec{\nabla} H[-]$ the hydraulic gradient, $\vec{n}$ the interface normal vector, $T_{i j}\left[\mathrm{~m}^{2} \mathrm{~s}^{-1}\right]$ the transmissivity at the interface and $L_{i j}[\mathrm{~m}]$ is the interface length.

$T_{i j}$ is computed at each time step by integrating the hydraulic conductivity along the interface according to $z$ between the bed rock and the water level (linearly interpolated between cells $i$ and $j$ ). In the case of layered soils, the wet thickness of each soil layers is considered for the calculation of transmissivity. If cells $i$ and $j$ have different geological properties, $T_{i j}$ is taken equal to the harmonic mean of the transmissivity computed for each cell.

A simple estimation of the hydraulic gradient at the interface as the head difference between cells $i$ and $j$ divided by the distance between the centroids of the cells would produce inaccurate results for non-rectangular cells. The use of irregular meshes can however be relevant to better fit the geometry of urban objects. To ensure the validity of the computation on such meshes, the approach relies on the use of a third cell $a$ to estimate the components of the hydraulic gradient along the interface (De Marsily, 1981) (Figure 1). The third cell is selected by limiting its distance from the interface and excluding cells whose centre of gravity would be close to an alignment with those of cells $i$ and $j$. Based on these three cells, a Taylor series expansion at the first order for any point $m$ on the interface gives:

$$
\left\{\begin{array}{l}
H_{i}=H_{m}+\left(x_{i}-x_{m}\right)\left(\frac{\delta H}{\delta x}\right)_{m}+\left(y_{i}-y_{m}\right)\left(\frac{\delta H}{\delta y}\right)_{m} \\
H_{j}=H_{m}+\left(x_{j}-x_{m}\right)\left(\frac{\delta H}{\delta x}\right)_{m}+\left(y_{j}-y_{m}\right)\left(\frac{\delta H}{\delta y}\right)_{m} \\
H_{a}=H_{m}+\left(x_{a}-x_{m}\right)\left(\frac{\delta H}{\delta x}\right)_{m}+\left(y_{a}-y_{m}\right)\left(\frac{\delta H}{\delta y}\right)_{m}
\end{array}\right.
$$


Where $H_{i}, H_{j}$ and $H_{m}$, are the hydraulic head within cell $i, j$ and on the interface, respectively, and $x_{i}, y_{i}, x_{j}, y_{j}, x_{m}$ and $y_{m}$, are the coordinates of the centre of gravity of cell $i, j$ and of the point $\mathrm{m}$, respectively.

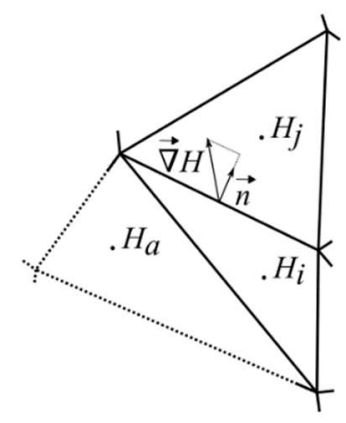

Figure 1: Computation of the hydraulic gradient at the interface between two cells $i$ and $j$ using a third cell a

The resolution of 2 provides the components of the hydraulic gradient at the interface:

$$
\left\{\begin{array}{l}
\left(\frac{\delta H}{\delta x}\right)_{m}=\frac{\left(H_{j}-H_{i}\right)\left(y_{a}-y_{i}\right)-\left(H_{a}-H_{i}\right)\left(y_{j}-y_{i}\right)}{\left(x_{j}-x_{i}\right)\left(y_{a}-y_{i}\right)-\left(x_{a}-x_{i}\right)\left(y_{j}-y_{i}\right)} \\
\left(\frac{\delta H}{\delta y}\right)_{m}=-\frac{\left(H_{j}-H_{i}\right)\left(x_{a}-x_{i}\right)-\left(H_{a}-H_{i}\right)\left(x_{j}-x_{i}\right)}{\left(x_{j}-x_{i}\right)\left(y_{a}-y_{i}\right)-\left(x_{a}-x_{i}\right)\left(y_{j}-y_{i}\right)}
\end{array}\right.
$$

$\vec{\nabla} H$ in Eq. 1 is then be obtained by projecting these components onto the normal at the interface:

$$
\vec{\nabla} H=\left(\frac{\delta H}{\delta x}\right)_{m} \cdot \vec{n}_{x}+\left(\frac{\delta H}{\delta y}\right)_{m} \cdot \vec{n}_{y}
$$

\subsubsection{Interactions with underground structures}

The modelling of interactions between GW and underground structures is inspired by urban hydrogeology methods. It relies on the use of either specific hydrodynamic parameters (e.g. for underground structure) or boundary conditions (BCs) (e.g. for drainage systems (Dirichlet BCs + flow constraint), for wells (Neuman BCs) or for sewer systems (Cauchy BCs)) (Attard et al., 2016b).

The modelling of underground constructions (buildings, car parks, etc.) is carried out by assigning to cells included in the structure perimeter a hydraulic conductivity of $10^{-9} \mathrm{~ms}^{-1}$ over the structure depth. If the structure is equipped with a drainage system, the volumes $V_{d r, i}\left[\mathrm{~m}^{3}\right]$ drained at each time step are computed according to Eq. 5. It aims to mimic a Dirichlet BC while limiting the flow by the surrounding medium and by a maximum permissible flow rate per unit area (pump limit).

$$
V_{d r, i}=\min \left(\left(H_{i}(t-\Delta t)-z_{d r, i}\right) S y, K s_{d r, i} \Delta t, Q_{\max } \Delta t, 0\right) A_{i}
$$

With $H_{i}[\mathrm{~m}]$ the GW level in cell $i, z_{d r, i}[\mathrm{~m}]$ the drainage system level, $S y$ [-] the specific yield (i.e. the difference between the total porosity and the specific retention, considered here equal to the field capacity), $K s_{d r, i}\left[\mathrm{~ms}^{-1}\right]$ the saturated hydraulic conductivity of soil below the basement, $A_{i}\left[\mathrm{~m}^{2}\right]$ the area of cell $i$ and $Q_{\max }\left[\mathrm{ms}^{-1}\right]$ the maximum flow rate per unit surface.

The volume $V_{\text {sew, } i}\left[\mathrm{~m}^{3}\right]$ drained by a sewer networks at each time step within a cell $i$ is determined by Eq. 6 . It aims to mimic a Cauchy BC.

$$
V_{\text {sew }, i}=\min \left(G_{\text {sew }, i}\left(H_{i}(t-\Delta t)-z_{\text {sew }, i}\right), 0\right) L_{\text {sew }, i} \Delta t
$$

With $G_{\text {sew, } i}\left[\mathrm{~ms}^{-1}\right]$ a coefficient characterizing the conductivity of the pipe and the surrounding medium, $z_{\text {sew }, i}[\mathrm{~m}]$ the pipe elevation and $L_{s e w, i}[\mathrm{~m}]$ the pipe length within cell $i$. 
Pumping and injection wells are modelled using a sink/source term $V_{\text {well, } i}\left[\mathrm{~m}^{3}\right]$ (corresponding to a given pumping/injection rate multiplied by the time step).

\subsubsection{Groundwater level update}

At the end of each time step, the GW level is updated according to Eq. 7.

$$
H_{i}(t)=H_{i}(t-\Delta t)+\left[\sum_{j=1}^{n}\left(V_{j i}(t)\right)-V_{d r, i}(t)-V_{\text {sew }, i}(t)+V_{w e l l, i}(t)+F_{U Z-S Z}(t) \Delta t\right] /\left(A_{i} S y_{i, l}\right)
$$

With $V_{j i}\left[\mathrm{~m}^{3}\right]$ the volume exchanged with the adjacent cell $j$ by lateral $\mathrm{GW}$ flow, $F_{U Z-S Z}\left[\mathrm{~ms}^{-1}\right]$ the exchange between UZ and SZ (section 2.2) and $S y_{i, l}$ [-] the specific yield of the geological layers where the water table movement occurs. Each groundwater level variation is calculated using the specific yield of the reservoir in which the variation occurs. If the water table changes reservoir, the calculation takes into account successively the specific yield of each reservoir crossed.

\subsection{Unsaturated zone}

The UZ is conceptualized as an overlay of reservoirs (Figure 2). Reservoirs may have identical hydrodynamic properties and thus constitute discretization elements or, conversely, they may have different properties in order to represent layered soils. The number and thickness of reservoirs are not fixed and are selected for each case based on material properties and modelling objectives.

The Brooks and Corey model (Brooks and Corey, 1964) is used to represent the relation between pressure, water content and hydraulic conductivity (Eq. 8).

$$
\begin{aligned}
& S e_{k}=\frac{\theta_{k}-\theta r_{k}}{\theta r_{k}-\theta s_{k}}= \begin{cases}{\left[\psi_{k} / \psi_{E, k}\right]^{1 / B_{k}}} & \text { if } \psi_{k} \leq \psi_{E, k} \\
1 & \text { if } \psi_{k}>\psi_{E, k}\end{cases} \\
& K_{k}\left(S e_{k}\right)=K s_{k} S e_{k}^{2 B_{k}+3}
\end{aligned}
$$

With $S e_{k}[-]$ the saturation rate, $\Psi_{k}[\mathrm{~m}]$ the capillary pressure, $\Psi_{E, k}[\mathrm{~m}]$ the capillary pressure at air entry value, $B_{k}[-]$ a shape parameters and $K s_{k}\left[\mathrm{~ms}^{-1}\right]$ the saturated hydraulic conductivity of reservoir $k . \theta_{k}[-], \theta s_{k}[-]$, and $\theta r_{k}[-]$ are respectively the water content, the saturated water content and the residual water content of reservoir $k$. 


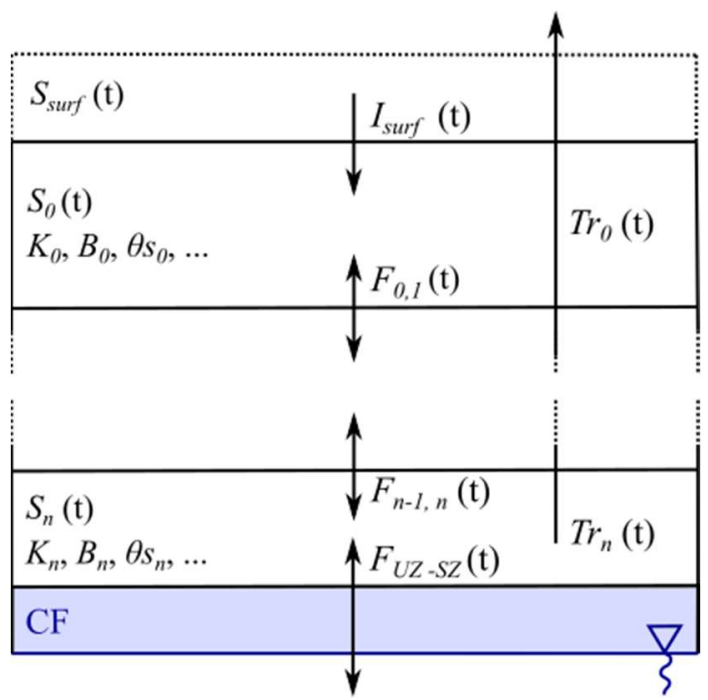

Figure 2: Unsaturated zone conceptualization into an overlay of reservoirs. The various notations are defined in section 2.2 and in the list of notations.

Following WEP's approach (Jia et al., 2001), vertical UZ fluxes computation is based on a coupling between a reservoir model and a Green-Ampt Model. The following sections detail the calculation of (1) the surface infiltration flux, (2) the vertical fluxes outside the infiltration front and (3) the conceptualization of the capillary fringe.

\subsubsection{Surface infiltration and Green-Ampt model}

The surface infiltration flux $I_{\text {surf }}\left[\mathrm{ms}^{-1}\right]$ depends on the soil's infiltration capacity. First of all, infiltration is assumed to be zero when the water table is at land surface. Apart from this case, $I_{\text {surf }}$ computation method depends on the ratio between the surface flux to be infiltrated $\left.i_{\text {sup }}=P(\mathrm{t})+S_{\text {surf }}(\mathrm{t}-\Delta \mathrm{t}) / \Delta \mathrm{t}\right)\left[\mathrm{ms}^{-1}\right]$ and the infiltration capacity $C a=\min$ $\left(K_{s, 0}, d_{0}\left(\theta s_{0}-\theta_{0}(\mathrm{t}-\Delta \mathrm{t})\right) / \Delta \mathrm{t}\right)\left[\mathrm{ms}^{-1}\right]$. With $P\left[\mathrm{~ms}^{-1}\right]$ the rainfall volume during the time step, $S_{\text {surf }}[\mathrm{m}]$ the surface storage and $K_{s, 0}\left[\mathrm{~ms}^{-1}\right], \mathrm{d}_{0}[\mathrm{~m}], \theta s_{0}[-]$ and $\theta_{0}[-]$ the saturated hydraulic conductivity, the thickness, the water content at saturation and the current water content of the upper reservoir, respectively. If $i_{s u p} \leq C a$, the incident volumes can be fully infiltrated and $I_{\text {surf }}=i_{\text {sup }}$. If $i_{\text {sup }}>C a, I_{\text {surf }}$ is computed using a Green-Ampt model adapted to layered soils (Jia and Tamai, 1997) in order to more accurately model the infiltration dynamics while taking into account layered soils and heterogeneous initial water content profiles. The Green-Ampt model calculation only occurs when $C a$ is exceeded which makes it possible to improve the estimation of infiltrated flow without significantly increasing the calculation time. This mode of activation (using $\mathrm{Ca}$ ) allows the use of the Green-Ampt model when a less permeable underlying reservoir limits the infiltration capacity. Indeed, if the infiltration rate is higher than the hydraulic conductivity of the less permeable reservoir, the water content within the upper reservoirs gradually increases (calculated by the reservoir model as described in section 2.2.2) until $i_{\text {sup }}>C a$.

When the Green-Ampt model is activated, the cumulative infiltration since the beginning of the activation $I$ [m] is computed as follows:

- If the surface remains unsaturated:

$I(t)-I(t-\Delta t)=i_{\text {sup }}(t) \Delta t$

- The surface ponding occurs if the surface volume to be infiltrated is greater than the volume estimated by the Green-Ampt model under saturated conditions: 
$I(t)=\frac{A_{m-1}}{i_{\text {sup }} / K s_{m}-1}-B_{m-1} \leq i_{\text {sup }} \Delta t+I(t-\Delta t)$

- If surface ponding occurs at the present time step:

$$
\begin{array}{r}
I_{p}-I(t-\Delta t)=i_{\text {sup }} t_{p} \rightarrow t_{p}=\frac{I_{p}-I(t-\Delta t)}{i_{\text {sup }}} \\
I(t)-I_{p}=K s_{m}\left(t-t_{p}\right)+A_{m-1} \ln \left(\frac{A_{m-1}+B_{m-1}+I(t)}{A_{m-1}+B_{m-1}+I_{p}}\right)
\end{array}
$$

- If surface ponding occurred during a previous time step and continues since:

$$
I(t)-I(t-\Delta t)=\min \left[i_{\text {sup }}(t) \Delta t, K s_{m} \Delta t+A_{m-1} \ln \left(\frac{A_{m-1}+B_{m-1}+I(t)}{A_{m-1}+B_{m-1}+I(t-\Delta t)}\right)\right]
$$

With $m$ the index of the reservoir where the infiltration front is located, $t_{p}[\mathrm{~s}]$ the duration between the beginning of the time step and the beginning of the surface ponding and $I_{p}[\mathrm{~m}]$ the cumulative infiltration from the activation of Green-Ampt model to the surface ponding. Other variables are described below:

$$
\begin{aligned}
A_{m-1} & =\left(\sum_{k=0}^{m-1} d_{k}-\sum_{k=0}^{m-1} d_{k} K s_{m} / K s_{k}+S W_{m}+S_{\text {surf }}\right) \Delta \theta_{m} \\
B_{m-1} & =\left(\sum_{k=0}^{m-1} d_{k} K s_{m} / K s_{k}\right) \Delta \theta_{m}-\sum_{k=0}^{m-1} d_{k} \Delta \theta_{k}
\end{aligned}
$$

With $d_{k}[\mathrm{~m}]$ the thickness of reservoir $k, S W_{m}$ the capillary pressure at the infiltration front lower limit (computed according to Eq. 14 using Brooks and Corey law), $\Delta \theta_{k}$ the difference between the saturated water content and the initial water content (i.e. at the time of activation of Green-Ampt model) in reservoir $k$.

$$
S W_{m}=\int_{0}^{\psi_{m}} \frac{K_{m}(\operatorname{Se}(\psi))}{K s_{m}} d \psi
$$

For more details regarding the derivation of Eq. 9 to 14, the reader may refer to (Jia and Tamai, 1997).

If the saturation front reaches a reservoir with a higher hydraulic conductivity, the inflow is not sufficient to saturate the new material and Green-Ampt model's applicability assumptions are no longer met. The Green-Ampt model is then applied only within the upper reservoirs according to Eq. 15 . The downflow at the reservoir bottom $F_{R M}\left[\mathrm{~ms}^{-1}\right]$, computed with the Green-Ampt model, is used as the upper limit condition for the reservoir model within the underlying reservoir. In any other case $F_{R M}=0 \mathrm{~ms}^{-1}$.

$$
I_{\text {surf }}=F_{R M}=K_{\text {eff }}\left(1+\left(S W_{m}+S_{\text {surf }}\right) / \sum_{k=0}^{m} d_{k}\right)
$$

With $K_{\text {eff }}\left[\mathrm{ms}^{-1}\right]$ the effective hydraulic conductivity of the medium above the saturation front (obtained by a harmonic mean of the saturated hydraulic conductivity of reservoir weighted by their thickness).

If the saturation front reaches the substratum or the GW table, infiltration stops and the GW level is fixed at soil surface. This amounts to considering that the saturated column belongs to the saturated zone and contributes to increase the hydraulic head.

\subsubsection{Unsaturated fluxes computation using the reservoir model}

Vertical fluxes between reservoirs and vegetation transpiration are computed using a reservoir model. When the Green-Ampt model is not activated, the fluxes are sequentially computed from the capillary fringe upper limit (reservoir $n$ ) to the ground surface (reservoir 0), on the basis of capillary pressures at the previous time step (Figure 
2). When the Green Ampt model is activated, exchanges between reservoirs are still computed up to the reservoir located under the one including the infiltration front in order to take into account fluxes under the front (in particular exchanges with the SZ). When the infiltration front computed by the Green-Ampt model enters a reservoir, the latter is excluded from the reservoir model computation. The water content within the reservoir is then used as initial water content in the Green-Ampt model for computing the progression of the infiltration front. Conversely, when the GreenAmpt model is disabled, the water content in the various reservoirs is updated by adding the additional volume of the infiltration front contained therein. This procedure ensures the water balance in UZ.

The balance equation for a given reservoir $\mathrm{k}$ between 0 and $\mathrm{n}$ is given by Eq. 16:

$$
S_{k}(t)=S_{k}(t-\Delta t)+\left(F_{k-1, k}(t)-F_{k, k+1}(t)-\operatorname{Tr}_{k}(t)\right) \Delta t
$$

With $S_{k}[\mathrm{~m}]$ the storage in reservoir $k, F_{k, k+1}\left[\mathrm{~ms}^{-1}\right]$ the exchange flux (gravity and diffusion) between reservoir $k$ and $k+1$ and $\operatorname{Tr}_{k}\left[\mathrm{~ms}^{-1}\right]$ the root water uptake flux in reservoir $k$. The computation of the various flux is subsequently described. Fluxes are limited by the storage of the incoming and outgoing reservoirs, so that the water content remains between its residual and saturation level.

The root water uptake flux $\operatorname{Tr}_{k}$, within reservoir $k$ is computed using the Feddes model (Feddes et al., 1978):

$$
\operatorname{Tr}_{k}(t)=\min \left(\frac{\psi_{k}(t-\Delta t)-\psi_{W P, k}}{\psi_{F C, k}-\psi_{W P, k}}, 1\right) d r_{k} E d(t)
$$

With $\Psi_{k}[\mathrm{~m}]$ the capillary pressure in reservoir $k$ computed according to Brooks and Corey's law, $\Psi_{W P, k}[\mathrm{~m}]$ and $\Psi_{F C, k}$ $[\mathrm{m}]$ the capillary pressure at wilting point (i.e. $-150 \mathrm{~m}$ ) and at field capacity (i.e. - $3.3 \mathrm{~m}$ ), respectively, $d r_{k}[-]$ the root density in the reservoir $k\left(\sum_{k} d r_{k}=1\right)$ and $E d\left[\mathrm{~ms}^{-1}\right]$ the evaporative demand.

Exchange flux between two reservoirs $F_{k, k+1}$ is computed according to Eq. 18. It takes into account gravity flux (first term in the bracket) and diffusion flux (second term in the bracket). Positive exchange fluxes are oriented downwards.

$$
F_{k, k+1}(t)=K_{k, k+1}(t)\left[1-\frac{\psi_{k+1}(t-\Delta t)-\psi_{k}(t-\Delta t)}{\left(d_{k}+d_{k+1}\right) / 2}\right]
$$

With $K_{k, k+1}\left[\mathrm{~ms}^{-1}\right]$ the average hydraulic conductivity at interface between reservoir $k$ and $k+1$ and $d_{k}$ the thickness of reservoir $k$. The calculation method of $K_{k, k+1}$ depends on whether the two reservoirs have identical or different hydrodynamic characteristics. If the reservoirs have identical hydrodynamic characteristics, $K_{k, k+1}$ is computed according to Brooks and Corey's law (Eq. 8) considering an average saturation $S e_{k, k+l}$. The latter is computed according to Eq. 19. It assumes that when the saturation rate of the upper reservoir is higher (i.e. in the case of marked downward flux), the saturation level of the upper reservoir governs the advance of the infiltration front.

$$
\operatorname{Se}_{k, k+1}(t)=\max \left(\operatorname{Se}_{k}(t),\left[\operatorname{Se}_{k}(t)+S e_{k+1}(t)\right] / 2\right)
$$

If the reservoirs have different hydrodynamic characteristics, $K_{k, k+l}$ is equal to the average hydraulic conductivity of the two reservoirs (Eq. 20) computed using the Brooks and Corey law (Eq. 8).

$$
K_{k, k+1}(t)=\left[K_{k}\left(S_{k}(t)\right)+K_{\mathrm{k}+1}\left(S_{\mathrm{k}+1}(t)\right)\right] / 2
$$


The limits of the chosen parameterizations as well as those associated with the use of other types of averages are discussed in supplementary material (section S1 and S3).

For the upper reservoir, $F_{k, k+1}$ is the surface infiltration $I_{\text {surf }}\left[\mathrm{ms}^{-1}\right]$ (section 2.2.1) if Green-Ampt model is deactivated or $F_{R M}$ otherwise. For the lowest reservoir $n, F_{k, k+1}$ is the exchange flux with the saturated zone $F_{U Z-S Z}\left[\mathrm{~ms}^{-1}\right]$. The latter is computed between the middle of the lower reservoir and the top of the capillary fringe (CF) according to Eq. 21 (which is a direct application of Eq. 18 within these conditions). The capillary pressure value at the top of the CF $\Psi_{C F}$ is by default equal to the air entry pressure. The special case of a material transition is detailed in the following section (2.2.3). Note that the thickness of this reservoir $d_{n}$ varies with the depth of the GW table (see section 2.3).

$$
F_{U Z-S Z}(t)=K_{n}\left(\left(S e_{n}(t-\Delta t)+1\right) / 2\right)\left(1-\frac{\psi_{\mathrm{CF}}-\psi_{n}(t-\Delta t)}{d_{n} / 2}\right)
$$

\subsubsection{Capillary fringe conceptualization}

As the Brooks and Corey model cannot model variably saturated soil within the capillary fringe ( $S e_{k}=1$ if $\Psi_{k}<\Psi_{E, k}$ ), the model assumes a conceptualization of the CF.

The CF is assumed to behave like a saturated zone. UZ-SZ exchanges through the CF are assumed to be instantaneous. The CF belongs to $\mathrm{UZ}$ and the corresponding water storage $S_{C F}[\mathrm{~m}]$ is then assigned to the $\mathrm{UZ}$ storage. By default, the CF thickness and the capillary pressure at its upper boundary $\Psi_{C F}$ are equal to the air entry pressure of the material $\Psi_{E, k}$.

For stratified soils, the model conceptualizes the influence of material transitions on the capillary fringe (Figure 3). Consider two superimposed geological layers $k$ and $k+1$ (with $k$ on top), one made of coarse material and the other of fine material, with the top of the water table located in the lower layer $(k+1)$. Consider $\Psi_{\text {int }}$ the capillary pressure at the interface at hydrostatic equilibrium condition (i.e. equal to the distance between the interface and the top of the water table) (Figure 3). To facilitate interpretation, the various pressures are expressed in absolute values in the remainder of this paragraph.
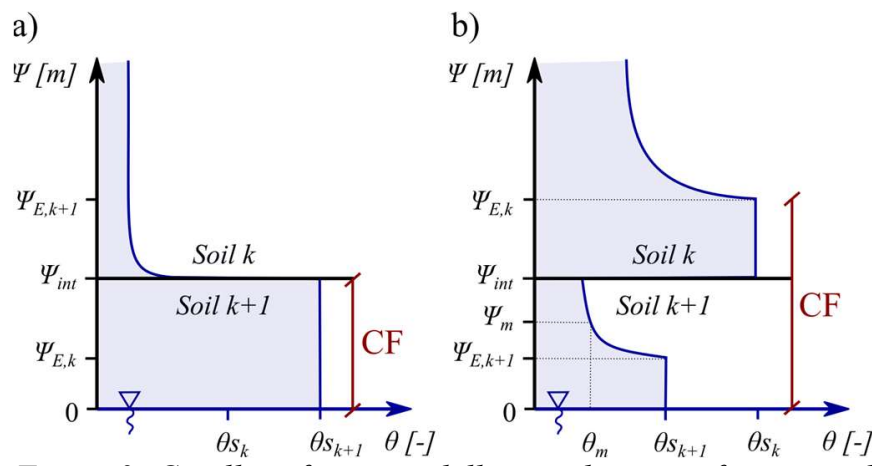

Figure 3: Capillary fringe modelling in the case of a material transition.

If the upper material is coarser than the lower one, then $\Psi_{E, k}<\Psi_{E, k+l}$ and $\Psi_{E, k}<\Psi_{\text {int }}<\Psi_{E, k+l}$ and $\theta_{k}\left(\Psi_{\text {int }}\right)<\theta s_{k}$. The CF upper boundary is thus fixed at the interface, its storage is $S_{C F}=\Psi_{i n t} \theta s_{k}$, and the pressure value used for $F_{U Z-S Z}$ computation is $\Psi_{C F}=\Psi_{\text {int }}$ (Figure 3a). 
If the lower material is coarser than the upper, then $\Psi_{E, k}>\Psi_{E, k+1}$ and $\Psi_{E, k+1}<\Psi_{\text {int }} \leq \Psi_{E, k}$ and the CF reaches the upper reservoir while the lower reservoir remains unsaturated over a $\Psi_{\text {int }}-\Psi_{E, k+1}$ thickness (Figure $3 \mathrm{~b}$ ). $\Psi_{C F}=\Psi_{E, k}$ and the CF storage is thus computed as follows: $S_{C F}=\left(\Psi_{E, k}-\Psi_{i n t}\right) \theta s_{k}+\left(\Psi_{i n t}-\Psi_{E, k+1}\right) \theta_{m}+\Psi_{E, k+1} \theta s_{k+1}$, considering an estimate of the mean water content within this thickness $\theta_{m}=\theta\left(\Psi_{m}\right)$ with $\Psi_{m}=\left(\Psi_{\text {int }}+\Psi_{E, k+1}\right) / 2$ (Figure $3 \mathrm{~b}$ ) computed according to Brooks and Corey law (Eq. 8).

\subsection{Computation procedure}

From the beginning of the time step, the computation follows the subsequent steps:

1. Computation of the various fluxes and storage related to the $\mathrm{UZ}$ for each cell (section 2.2).

2. Computation of the interactions between GW and underground structures for each cell (section 2.1).

3. Computation of GW flows for each interface between cells (section 2.1).

4. Update of the GW level according to Eq. 7 for each cell considering the specific yield of each reservoir intersected by the water table movement.

5. Update of the CF level for each cell (section 2.2.3).

6. Update of the thickness of the lower reservoir for each cell accordingly to the new CF level. In order to avoid numerical oscillations, the thickness cannot fall below a threshold $d_{\min }[\mathrm{m}]$, typically about a few centimetres, informed by the user and depending on the material properties. Below this threshold, the reservoir is merged with the upper reservoir.

7. Update of the water content in the UZ for each cell. Indeed, as GW movements (and consequently CF movements) are determined on the basis of fixed specific yields, maintaining the balance requires a reallocation of the UZ volume located in the variation thickness of GW. Additionally, in the case of layered soils, the CF storage may vary within a time step as presented in section 2.2.3. The sum of these two differences (positive or negative) is added to the overlying reservoirs and its water content is updated. If it leads to exceeding the water content at saturation, the excess is added to the overlying reservoir, and so on until the surface if all the reservoirs are saturated. Conversely, if it leads to fall below the residual water content the corresponding deficit is spread over the overlying reservoir. If it cannot be distributed over the soil column, the water table level is lowered accordingly.

\section{Evaluation of the subsurface modelling approach}

The modules are evaluated over a set of hypothetical test cases. The evaluation is based on a comparison between the results provided by the modules and those obtained by reference models: HYDRUS 1D (Šimůnek et al., 2005) for the 1D fluxes in unsaturated zone and FEFLOW (Diersch, 2014) for the GW flows and the coupling between UZ and SZ modules. Results are compared over a set of variables distributed either in time (e.g. infiltration, GW level fluctuations at one point) or in space (e.g. GW levels at steady state). Comparison variables are specified in the corresponding test case subsections. The error related to spatial distributions of variables is quantified focusing on the mean absolute error $\left|E_{x y}\right|_{\text {mean }}$ (Eq. 22) and the maximum absolute error $\left|E_{x y}\right|_{\max }$ (Eq. 23). Due to the difference in spatial discretization, the results are interpolated for comparison on a regular G grid composed of 250000 points spaced one meter apart. 


$$
\begin{aligned}
\left|E_{x y}\right|_{\text {mean }} & =\sum_{(x, y) \in G}\left|X(x, y)-X_{\text {ref }}(x, y)\right| / 250000 \\
\left|E_{x y}\right|_{\text {max }} & =\max _{(x, y) \in G}\left|X(x, y)-X_{\text {ref }}(x, y)\right|
\end{aligned}
$$

With $X$ and $X_{\text {ref }}$ the variable simulated by the modules presented in this study and the reference model, respectively. The error related to temporal distributions of variables is quantified focusing on the mean absolute error $\left|E_{t}\right|_{\text {mean }}(\mathrm{Eq}$. 24) and the determination criteria $R^{2}$ (Eq. 25).

$$
\begin{aligned}
& \left|E_{t}\right|_{\text {mean }}=\sum_{t=0}^{n}\left|X(t)-X_{\text {ref }}(t)\right| / n \\
& R^{2}=\frac{\left[\sum_{t=0}^{n}(X(t)-\bar{X})\left(X(t)-\overline{X_{\text {ref }}}\right)\right]^{2}}{\sum_{t=0}^{n}(X(t)-\bar{X})^{2} \sum_{t=0}^{n}\left(X_{\text {ref }}(t)-\overline{X_{\text {ref }}}\right)^{2}}
\end{aligned}
$$

The test cases are divided into three categories depending on whether they focus on the SZ (subsection 3.1), the UZ (subsection 3.2) or the coupled SZ+UZ system (subsection 3.3). Table 1 lists the characteristics of the various soils used, chosen to cover a wide range of soils encountered in the literature (Morris and Johnson, 1967). Table 2 summarizes the main characteristics of the various test cases.

\begin{tabular}{|c|c|c|c|c|c|c|c|c|}
\hline Soil type & $K s\left[\mathrm{mmh}^{-1}\right]$ & $S y[-]$ & $\Theta s[-]$ & $\Theta r[-]$ & $\Theta_{F C}[-]$ & $\Theta_{W P}[-]$ & $B[-]$ & $\Psi_{E}[\mathrm{~m}]$ \\
\hline Gravel & 3600 & 0.25 & - & - & - & - & - & - \\
\hline Coarse sand & 360 & 0.30 & - & - & - & - & - & - \\
\hline Fine sand & 36 & 0.20 & - & - & - & - & - & - \\
\hline Sand & 210 & 0.37 & 0.44 & 0.02 & 0.06 & 0.02 & 1.69 & 0.07 \\
\hline Sandy loam & 26 & 0.26 & 0.45 & 0.04 & 0.19 & 0.09 & 3.11 & 0.15 \\
\hline Silt & 6.8 & 0.21 & 0.50 & 0.02 & 0.29 & 0.14 & 4.74 & 0.21 \\
\hline Silty clay loam & 4.3 & 0.13 & 0.47 & 0.06 & 0.34 & 0.21 & 6.62 & 0.33 \\
\hline Clay & 0.6 & 0.10 & 0.48 & 0.09 & 0.38 & 0.27 & 7.63 & 0.37 \\
\hline
\end{tabular}

Table 1: Properties of the soil used in the various test cases. Gravel, coarse sand, and fine sand are only used in the saturated module evaluation and are characterized solely by the parameters used in this module.

\subsection{Evaluation of the saturated zone modelling approach}

Three test cases are dedicated to the evaluation of the SZ modelling approach presented in section 2.1. For this evaluation, the SZ module is decoupled from the other modules. GW flows are computed with a fixed time step of 6 min (time step usually used in the URBS model and corresponding to rainfall data provided by the French national meteorological service). The various meshes are made up of irregular elements with and refinement in the vicinity of sharp variations in flow conditions. All the meshes used are shown in section S2 of the supplementary material.

The three test cases are based on a hypothetical $500 \mathrm{~m}$ x $500 \mathrm{~m}$ aquifer with a thickness of $10 \mathrm{~m}$. The slope of the surface and bedrock is $0.5 \%$. Except for test case SZ1, the medium is homogeneous and made of coarse sand. The $\mathrm{GW}$ level is set at a $2 \mathrm{~m}$ depth at the upstream and downstream boundaries so that the surface of the GW table is parallel to the model's top and bottom at natural steady state for a homogeneous medium.

\subsubsection{Test case SZ1: ability to simulate groundwater flows in a heterogeneous aquifer}

Test case SZ1 aims to evaluate the model's ability to reproduce steady state GW flow in the case of abrupt lateral variations in the surrounding environment such as changes in geological material or local anthropogenic 
modifications of the environment. The aquifer is therefore divided into three zones of varying hydraulic conductivity and specific yield as described in Figure 4a.

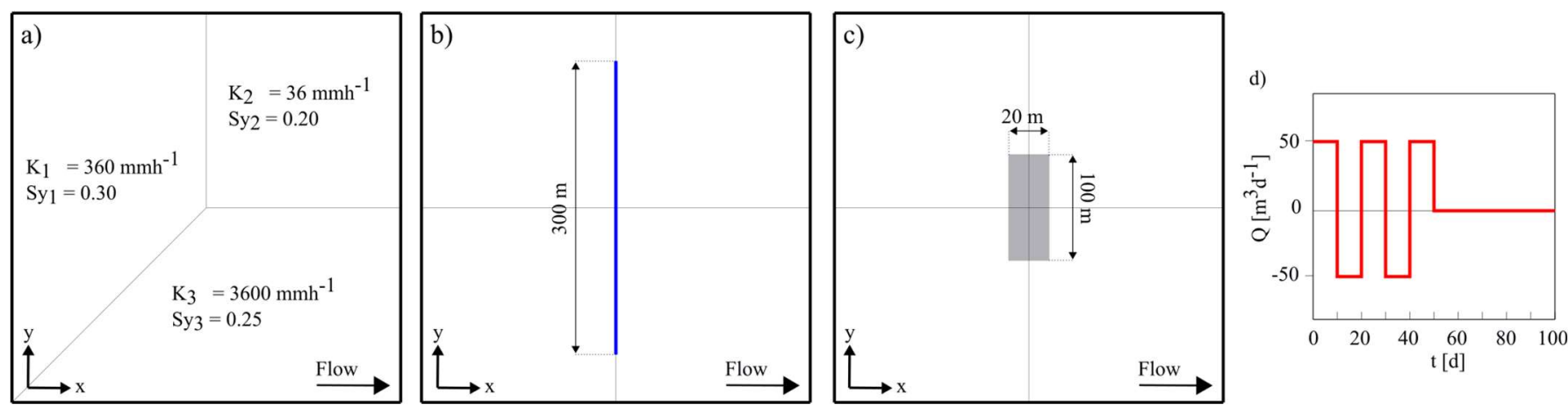

Figure 4: Definition of test cases dedicated to the evaluation of the saturated zone representation module. Geometry of test cases SZ1 (a), SZ3a (b), SZ3b and SZ3c (c) and operation of the injection/pumping well used in test case SZ2. 


\begin{tabular}{|c|c|c|c|c|c|c|}
\hline Ref. & Phenomena assessed & Domain properties & Flow conditions & Inputs & Spatio-temporal discretization & Ref. model \\
\hline SZ1 & $\begin{array}{l}\text { GW flow in a } \\
\text { heterogeneous aquifer }\end{array}$ & $\begin{array}{l}\text { - 500x500x10m parallelogram, constant slope }(0.5 \%) \\
\text { - Heterogeneous soil; } 3 \text { areas: gravel }\left(\mathrm{K}=3600 \mathrm{mmh}^{-1}\right) \text {, } \\
\text { coarse sand }\left(\mathrm{K}=360 \mathrm{mmh}^{-1}\right) \text {, fine sand }\left(\mathrm{K}=36 \mathrm{mmh}^{-}\right. \\
\text {1)) }\end{array}$ & $\begin{array}{l}\text { - Upstream and downstream: fixed head }(2 \mathrm{~m} \\
\text { below the soil surface) } \\
\text { - Other boundaries: no flux }\end{array}$ & - & \multirow{3}{*}{$\begin{array}{l}\text { - SZ module: Fixed time step of } 6 \\
\text { min; 2D irregular meshes with } \\
\text { refinement in the vicinity of the } \\
\text { disturbances; } 141 \text { to } 453 \text { cells } \\
\left(\sim 20 \mathrm{~m}^{2} \text { to } \sim 4000 \mathrm{~m}^{2}\right) \\
\\
\text { - FEFLOW: Variable time step; 3D } \\
\text { triangle mesh refined vertically and } \\
\text { horizontally in the vicinity of the } \\
\text { disturbances; Horizontal: } 58481 \\
\text { cells }\left(\sim 0.04 \mathrm{~m}^{2} \text { to } \sim 100 \mathrm{~m}^{2}\right) ; \\
\text { Vertical: } 10(1 \mathrm{~m} \text { thick) to } 12 \text { layers } \\
\text { (SZ3a }-0.5 \text { to } 1 \mathrm{~m} \text { thick) }\end{array}$} & \multirow[t]{3}{*}{$\begin{array}{l}\text { FEFLOW } \\
\text { 3D Darcy }\end{array}$} \\
\hline SZ2 & $\begin{array}{l}\text { GW fluctuations around } \\
\text { source/sink terms }\end{array}$ & $\begin{array}{l}\text { - 500x500x10m parallelogram, constant slope }(0.5 \%) \\
\left.\text { - Homogeneous soil (coarse sand: } \mathrm{K}=360 \mathrm{mmh}^{-1}\right) \\
\text { - Fully penetrating well at the domain centre }\end{array}$ & $\begin{array}{l}\text { - SZ1 BCs + variable flux on the well (see } \\
\text { inputs) } \\
\text { - Initial condition: natural steady state (linear } \\
\text { head decrease between the BCs, i }=0.5 \% \text { ) }\end{array}$ & $\begin{array}{l}\mathrm{Q}_{\text {well }}(\mathrm{t})=\{50 /-50 / 50 /-50 / 50 / 0\} \mathrm{m}^{3} \\
\mathrm{~d}^{-1} \text { during }\{10 / 10 / 10 / 10 / 10 / 50\} \mathrm{d}\end{array}$ & & \\
\hline SZ3 & $\begin{array}{l}\text { GW flow disturbances by } \\
\text { underground structures }\end{array}$ & $\begin{array}{l}\text { - 500x500x10m parallelogram, constant slope }(0.5 \%) \\
\left.\text { - Homogeneous soil (coarse sand: } \mathrm{K}=360 \mathrm{mmh}^{-1}\right) \\
\text { - Underground structures at the domain centre: } \\
\text { * SZ3a. 300m sewer pipe }\left(4 \mathrm{~m} \text { deep, } G_{\text {sew }}=10^{-5} \mathrm{~ms}^{-1}\right) \\
\text { * SZ3b. 100x20x6m basement }\left(\mathrm{K}=10^{-9} \mathrm{~ms}^{-1}\right) \\
\text { * SZ3c. SZ3b basement with drainage system }\end{array}$ & $\begin{array}{l}\text { - SZ1 BCs }+ \\
\text { * SZ3a. mixed BC on the sewer pipe } \\
\text { * SZ3c. fixed head on the drainage system } \\
\text { (6m below the soil surface) } \\
\text { - Initial condition: natural steady state }\end{array}$ & - & & \\
\hline UZ1 & Upward capillary rise & $\begin{array}{l}-2 \mathrm{~m} \text { homogeneous soil column (silt: } \mathrm{K}=6.8 \mathrm{mmh}^{-1} \text { ) } \\
-50 \mathrm{~cm} \text {-root zone }\end{array}$ & $\begin{array}{l}\text { - Lower BC: fixed head }(0 \mathrm{~m}) \\
\text { - Upper BC: no flux (see inputs) } \\
\text { - Root zone: variable PET (see inputs) } \\
\text { - Initial condition: hydrostatic equilibrium } \\
\text { state of the water content profile }\left(\mathrm{h}_{\text {bottom }}=0 \mathrm{~m}\right)\end{array}$ & $\begin{array}{l}\mathrm{Ed}(\mathrm{t})=\{0 / 0.2 / 0 / 0.2\} \mathrm{mmh}^{-1} \\
\text { during }\{30 / 30 / 30 / 30\} \mathrm{d}\end{array}$ & \multirow{3}{*}{$\begin{array}{l}\text { - UZ module: Fixed time step of } 6 \\
\text { min; Soil columns homogeneously } \\
\text { discretized into } 0.5 \mathrm{~m} \text { thick } \\
\text { reservoirs (4 to } 8 \text { reservoirs); Fixed } \\
\text { time step of } 6 \text { min } \\
\text { - HYDRUS } 1 D \text { : Variable time step; } \\
\text { soil columns homogeneously } \\
\text { discretized into nodes spaced } 0.5 \mathrm{~cm} \\
\text { apart }\end{array}$} & \multirow[t]{3}{*}{$\begin{array}{l}\text { HYDRUS } \\
1 \mathrm{D}\end{array}$} \\
\hline UZ2 & $\begin{array}{l}\text { UZ storage and fluxes } \\
\text { evolution in homogeneous } \\
\text { and layered soils under } \\
\text { various rainfall intensities }\end{array}$ & $\begin{array}{l}\text { - 3m soil column } \\
\text { * UZ2a. Homogeneous: silt }\left(\mathrm{K}=6.8 \mathrm{mmh}^{-1}\right) \\
\text { * UZ2b. Heterogeneous: silt }\left(0.5 \mathrm{~m}, \mathrm{~K}=6.8 \mathrm{mmh}^{-1}\right) \\
\text { over sand }\left(2.5 \mathrm{~m}, \mathrm{~K}=210 \mathrm{mmh}^{-1}\right) \\
\text { * UZ2c. Heterogeneous: silt }\left(0.5 \mathrm{~m}, \mathrm{~K}=6.8 \mathrm{mmh}^{-1}\right) \\
\text { over clay }\left(2.5 \mathrm{~m}, \mathrm{~K}=0.6 \mathrm{mmh}^{-1}\right) \\
\text { - } 25 \mathrm{~cm} \text {-root zone }\end{array}$ & $\begin{array}{l}\text { - Lower BC: fixed head }(0 \mathrm{~m}) \\
\text { - Upper BC: variable flux (see inputs) } \\
\text { - Root zone: variable PET (see inputs) } \\
\text { - Initial condition: hydrostatic equilibrium } \\
\text { state of the water content profile }\left(\mathrm{h}_{\text {bottom }}=0 \mathrm{~m}\right)\end{array}$ & $\begin{array}{l}-\mathrm{P}(\mathrm{t})=\{0 / 1 / 0 / 6.8 / 0 / 15 / 0\} \mathrm{mm} \mathrm{h}^{-1} \\
\mathrm{during}\{10 / 10 / 10 / 10 / 10 / 10 / 10\} \mathrm{d} \\
-\mathrm{Ed}(\mathrm{t})=\{0.2 / 0 / 0.2 / 0 / 0.2 / 0 / 0.2\} \\
\mathrm{mm}^{-1} \text { during } \\
\{10 / 10 / 10 / 10 / 10 / 10 / 10\} \mathrm{d}\end{array}$ & & \\
\hline $\mathrm{CO} 1$ & $\begin{array}{l}\text { Interactions between } \\
\text { water table variation and } \\
\text { UZ in a single soil column }\end{array}$ & $\begin{array}{l}\text { - } 4 \mathrm{~m} \text { soil columns: } \\
* \text { CO1a. Homogeneous: silt }\left(\mathrm{K}=6.8 \mathrm{mmh}^{-1}\right) \\
* \text { CO1b. Heterogeneous: silt }\left(2.5 \mathrm{~m}, \mathrm{~K}=6.8 \mathrm{mmh}^{-1}\right) \\
\text { over sand }\left(1.5 \mathrm{~m}, \mathrm{~K}=210 \mathrm{mmh}^{-1}\right) \\
\text { * CO1c. Heterogeneous: sand }\left(2.5 \mathrm{~m}, \mathrm{~K}=210 \mathrm{mmh}^{-1}\right) \\
\text { over silt }\left(1.5 \mathrm{~m}, \mathrm{~K}=6.8 \mathrm{mmh}^{-1}\right)\end{array}$ & $\begin{array}{l}\text { - Lower BC: variable flux (see inputs) } \\
\text { - Upper BC: variable flux (see inputs) } \\
\text { - Initial condition: hydrostatic equilibrium } \\
\text { state of the water content profile }\left(\mathrm{h}_{\text {bottom }}=1 \mathrm{~m} \text { ) }\right.\end{array}$ & $\begin{array}{l}-\mathrm{P}(\mathrm{t})=\{1 / 0 / 0 / 0 / 0\} \mathrm{mmh}^{-1} \text { during } \\
\{15 / 15 / 15 / 15 / 90\} \mathrm{d} \\
-\mathrm{Qb}(\mathrm{t})=\{0 /-0.5 / 0.5 /-1 / 0\} \mathrm{mmh}^{-1} \\
\text { during } \\
\{15 / 15 / 15 / 15 / 90\} \mathrm{d}\end{array}$ & & \\
\hline $\mathrm{CO} 2$ & $\begin{array}{l}\text { Water table evolution } \\
\text { under spatially } \\
\text { homogeneous or } \\
\text { heterogeneous rainfall }\end{array}$ & $\begin{array}{l}\text { - 500x500x20m parallelogram, constant slope }(0.5 \%) \\
\left.\text { - Homogeneous soil (silt: } \mathrm{K}=6.8 \mathrm{mmh}^{-1}\right)\end{array}$ & $\begin{array}{l}\text { - SZ1 BCs (at a 3m depth)+ } \\
\text { * CO2a. spatially homogeneous variable flux } \\
\text { at upper BC (see inputs) } \\
* \text { CO2b. spatially heterogeneous variable flux } \\
\text { at upper BC (see inputs) } \\
\text { - Initial condition: linear head decrease } \\
\text { between the BCs }(\mathrm{i}=0.5 \% \text { ) and hydrostatic } \\
\text { equilibrium state of the water content profile }\end{array}$ & $\begin{array}{l}-\mathrm{P}_{1}(\mathrm{t})=\{0.1 / 0 / 0.1 / 0 / 0.1 / 0\} \mathrm{mmh}^{-1} \\
\text { during }\{10 / 10 / 10 / 10 / 10 / 50\} \mathrm{d} \\
-\mathrm{P}_{2}(\mathrm{t})=\{1 / 0 / 1 / 0 / 1 / 0\} \mathrm{mmh}^{-1} \\
\text { during }\{10 / 10 / 10 / 10 / 10 / 50\} \mathrm{d}\end{array}$ & $\begin{array}{l}\text { - coupling: Fixed time step of } 6 \mathrm{~min} ; \\
\text { Horizontal: } 625 \text { square cells } \\
\left(400 \mathrm{~m}^{2}\right) ; \text { Vertical: first } 4 \mathrm{~m} \\
\text { homogeneously discretized into } \\
0.5 \mathrm{~m} \text { reservoirs } \\
\\
\text { - FEFLOW: Variable time step; 3D } \\
\text { triangle mesh; Horizontal: } 40000 \\
\text { triangle cells }\left(\sim 6 \mathrm{~m}^{2}\right) ; \text { Vertical: } 93 \\
\text { layers }(0.05 \mathrm{~m} \text { to } 1 \mathrm{~m} \text { thick })\end{array}$ & $\begin{array}{l}\text { FEFLOW } \\
\text { 3D } \\
\text { Richards }\end{array}$ \\
\hline
\end{tabular}

Table 2: Summary of the main characteristics of the test cases. 
The assessment is based on a comparison with results provided by the FEFLOW model solving the Darcy's law 3D equations. The domain is discretized horizontally into triangular elements with a refinement near to material transitions and vertically into $1 \mathrm{~m}$-thick layers. The comparison focuses on the steady-state distributed GW levels $\left(H_{x y}\right)$, considering the mean and maximum value of the absolute error (respectively $\left|E_{x y}\right|_{\operatorname{mean}}$ (Eq. 22) and $\left|E_{x y}\right|_{\max }$ (Eq. 23)).

\begin{tabular}{|c|c|}
\hline \multicolumn{2}{|c|}{$\mathrm{H}_{x y}[\mathrm{~m}]$} \\
\hline$\left|E_{x y}\right|_{\text {mean }}$ & $\left|E_{x y}\right|_{\max }$ \\
\hline 0.024 & 0.119 \\
\hline
\end{tabular}

Table 3: Comparison results between the simulation outputs from the SZ module and the FEFLOW model for the SZ1 test case.

Figure 7a shows the comparison between the steady state groundwater levels simulated by FEFLOW and the SZ module. Over the whole domain, the maximum error is about $12 \mathrm{~cm}$ and the mean error is about $2.5 \mathrm{~cm}$ (Table 3), which is reasonable considering the uncertainties related to the composition of the underground compartment or to measurements. The model slightly underestimates the water level in the most permeable part (lower part in Figure 5a). The maximal error is located at the transition between materials, near the upstream boundary condition, and gradually decreases downstream. The mesh refinement here maintains a satisfactory level of error without excessively increasing the number of elements. As shown in section S3.1 of the supplementary material, the estimation tends towards the reference result when the mesh is more refined.
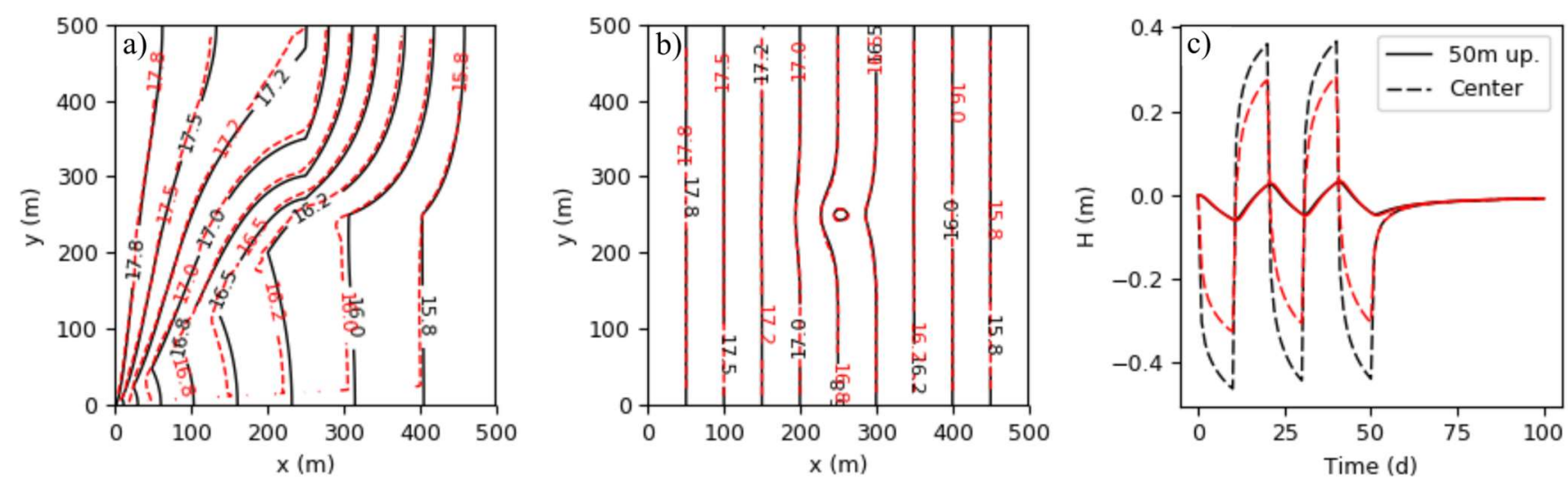

Figure 5: Groundwater levels computed by the SZ module (red lines) and FEFLOW (black lines) for test cases SZ1 and SZ2. a) Steady-state groundwater levels in a heterogeneous aquifer (case SZ1). b) Groundwater levels after 50 days around a pumping/injecting well (case SZ2). c) Groundwater level (H) evolution at the well location and $50 \mathrm{~m}$ upstream (case SZ2).

\subsubsection{Test case SZ2: ability to simulate groundwater fluctuations around sinks/sources}

Test case SZ2 is designed to assess the module's ability to simulate sharp transitory disturbances of GW level generated by a source/sink term such as injection/pumping well or concentrated water inflows from infiltration devices. A well is therefore added in the domain centre. Its operation is described in Figure 4d.

The assessment is based on a comparison with results provided by the FEFLOW model solving the Darcy 3D. The domain is discretized horizontally into triangular elements with a refinement near to the well and vertically into $1 \mathrm{~m}$ thick layers. The well is modelled in the FEFLOW model using a multilayer well BCs. The evaluation focuses on:

- the spatial distribution of GW levels $\left(H_{x y}\right)$ after at $\mathrm{t}=50 \mathrm{~d}$ (end of the well's operation), considering the mean absolute error (|$\left.E_{x y}\right|_{\text {mean }}$ (Eq. 22)) and the maximal absolute error ( $\left|E_{x y}\right|_{\max }$ (Eq. 23)); 
- the temporal evolution of GW levels at the well location $\left(H_{t \text { - center }}\right)$ and $50 \mathrm{~m}$ upstream $\left(H_{t-50 m}\right.$ up $)$, considering the mean absolute error $\left|E_{t}\right|_{\text {mean }}$ (Eq. 24) and the determination criteria $R^{2}$ (Eq. 25).

\begin{tabular}{|c|c|c|c|c|c|c|}
\cline { 2 - 7 } \multicolumn{1}{c|}{} & \multicolumn{2}{c|}{$H_{x y}[\mathrm{~m}]$} & \multicolumn{2}{c|}{$H_{t \text { - center }}[\mathrm{m}]$} & \multicolumn{2}{c|}{$H_{t-50 \text { up }}[\mathrm{m}]$} \\
\cline { 2 - 7 } \multicolumn{1}{c|}{} & $\left|E_{x y}\right|_{\text {mean }}$ & $\left|E_{x y}\right|_{\text {max }}$ & $\left|E_{t}\right|_{\text {mean }}$ & $R^{2}$ & $\left|E_{t}\right|_{\text {mean }}$ & $R^{2}$ \\
\hline SZ2 & 0.001 & 0.133 & 0.057 & 0.985 & 0.002 & 0.990 \\
\hline
\end{tabular}

Table 4: Comparison results between the simulation outputs from the SZ module and the FEFLOW model for the SZ2 test case Results related to this test case (Figure $5 \mathrm{~b}$ and $\mathrm{c}$ and Table 4) show that the module satisfactorily reproduces the influence of a sink/source term on GW levels. The maximal error $(\sim 13 \mathrm{~cm})$ is located in the vicinity of the well. It is directly related to the homogenization of the injected/pumped volumes over the cell surface (here about $400 \mathrm{~m} 2$ ). Greater accuracy would therefore be achieved by reducing the size of the well cell (see section S3.1 of the supplementary material). However, the low average error and the good matching of head isolines show that the error is quickly smoothed on adjacent cells. These various observations are confirmed by the comparison of GW level evolution at the domain centre and $50 \mathrm{~m}$ upstream (Figure $5 \mathrm{c}$ ).

\subsubsection{Test case SZ3: ability to simulate interactions between groundwater and underground structures}

Test case SZ3 aims to evaluate the module's ability to estimate interactions between GW and underground structures through three sub-cases focusing on: a sewer pipe (SZ3a), an impervious building basement (SZ3b) and a building basement equipped with a draining system (SZ3c). In test case SZ3a, a $300 \mathrm{~m}$ sewer pipe $\left(G_{\text {sew }}=10^{-5} \mathrm{~ms}^{-1}\right)$ is added in the central part of the domain, perpendicular to the direction of flow (Figure $4 \mathrm{~b}$ ) and at a depth of $4 \mathrm{~m}$. In test case SZ3b and SZ3c a building extending $100 \mathrm{~m} \times 20 \mathrm{~m}$ and $6 \mathrm{~m}$ deep (two underground floors) is added in the central part of the domain (Figure 4c). In case SZ3c, the building is equipped with a draining system to lower the GW level to a depth of $6 \mathrm{~m}$.

The assessment is based on a comparison with results provided by the FEFLOW model solving the Darcy's law in 3D equations. The domain is discretized horizontally into triangular elements with a refinement near to the underground structures and vertically into $1 \mathrm{~m}$-thick layers. The sewer pipe is modelled by assigning a Cauchy boundary condition over a $0.5 \mathrm{~m}$ x $300 \mathrm{~m}$ horizontal strip. The building's basement is modelled by assigning a hydraulic conductivity of $10^{-9} \mathrm{~ms}^{-1}$ to cells within the building's perimeter. The building's drainage system is modelled by applying a Dirichlet boundary condition on the horizontal elements located at the basement bottom. The evaluation focuses on:

- the spatial distribution of steady-state GW levels $\left(H_{x y}\right)$, considering the mean absolute error $\left(\left|E_{x y}\right|\right.$ mean $($ Eq. 22)) and the maximal absolute error ( $\left|E_{x y}\right|_{\max }$ (Eq. 23));

- the temporal evolution of GW volumes drained by the sewer pipe and the draining system $\left(V_{t}\right)$, considering the mean absolute error $\left|E_{t}\right|_{\text {mean }}$ (Eq. 24) and the determination criteria $R^{2}$ (Eq. 25).

\begin{tabular}{|c|c|c|c|c|}
\cline { 2 - 5 } \multicolumn{1}{c|}{} & \multicolumn{2}{c|}{$H_{x y}[\mathrm{~m}]$} & \multicolumn{2}{c|}{$V_{t}\left[\mathrm{~m}^{3} \mathrm{~d}^{-1}\right]$} \\
\cline { 2 - 5 } \multicolumn{1}{c|}{} & $\left|E_{x y}\right|_{\text {mean }}$ & $\left|E_{x y}\right|_{\text {max }}$ & $\left|E_{t}\right|_{\text {mean }}$ & $R^{2}$ \\
\hline SZ3a & 0.009 & 0.048 & 4.554 & 0.999 \\
\hline SZ3b & 0.002 & 0.033 & - & - \\
\hline SZ3c & 0.071 & 0.568 & 36.418 & 0.981 \\
\hline
\end{tabular}

Table 5: Comparison results between the simulation outputs from the SZ module and the FEFLOW model for the test cases SZ3 a to $\mathrm{c}$. 

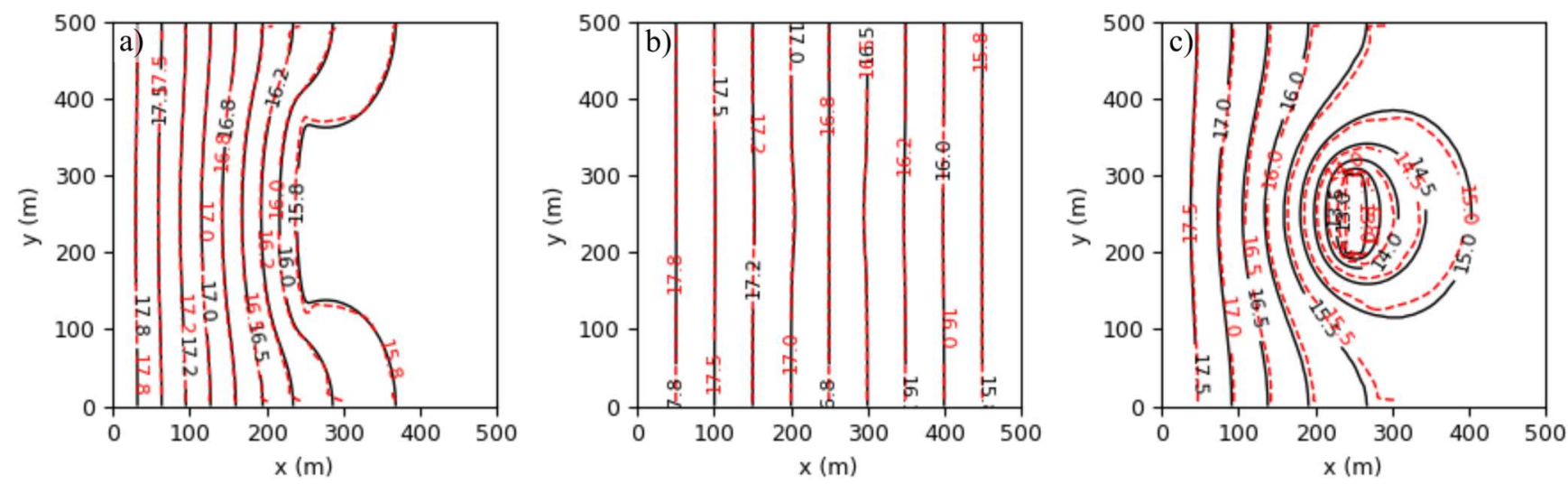

Figure 6: Groundwater levels computed by the SZ module (red lines) and FEFLOW (black lines) for test cases SZ3 a to c. a) Steady-state groundwater levels around a sewer network (case SZ3a). b) Steady-state groundwater levels around an impervious building basement (case SZ3b). c) Steady-state groundwater levels around a building basement equipped with a draining system (case SZ3b).

Results related to test case SZ3a to c are shown in Table 5 and Figure 6. The influence of the sewer pipe (Test case SZ3a) on steady-state GW levels is satisfactorily reproduced despite a slight overestimation in the vicinity of the structure (Table 5, Figure 6a). As for the well, it is linked to the distribution of infiltrated flows over a large area. The module also well estimates the dynamics of GW drainage through the pipe (Table 5, Figure $6 \mathrm{~b}$ ). The influence of the impervious basements (Test case SZ3b) is satisfactorily estimated. However, results are significantly less good for the basement equipped with a draining system (Test case SZ3c - Table 5, Figure 6c). If the flow shape is overall well reproduced, the error is significantly greater than in the previous cases (up to $57 \mathrm{~cm}$ in the vicinity of the building) and Figures $6 \mathrm{c}$ shows slight deformations of the head isolines in the vicinity of the basement (e.g. at $(\mathrm{x}=300, \mathrm{y}=$ 150)). Additionally, the model strongly underestimates the GW drainage by the draining system at the beginning of the simulation, although the steady-state drainage flows are well estimated (Table 5, Figure 7). These two observations reflect the insufficient refinement of the discretization near the building regarding the strong hydraulic gradients it generates (see section S3.1 of the supplementary material).

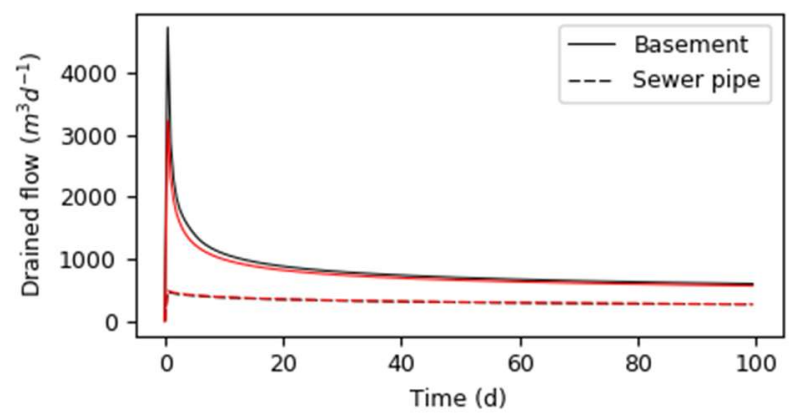

Figure 7: Groundwater volumes drained by the sewer pipe and the basement equipped with a draining system, simulated by the SZ model (red lines) and FEFLOW (black lines)

\subsection{Evaluation of the unsaturated zone modelling approach}


Three test cases are dedicated to the evaluation of the UZ modelling approach presented in section 2.2. For this evaluation, the UZ module is decoupled from the other modules. The various processes are computed with a constant time step of $6 \mathrm{~min}$. Soil columns are discretized into $0.5 \mathrm{~m}$ reservoirs. In order to maintain a constant level of the water table level at the column bottom (imposed pressure head equal to $0 \mathrm{~m}$ ), the computation of $I_{\text {surf }}$ and $F_{U Z-S Z}$ when the GA infiltration front reaches the water table is done according to Eq. 15, considering a zero suction.
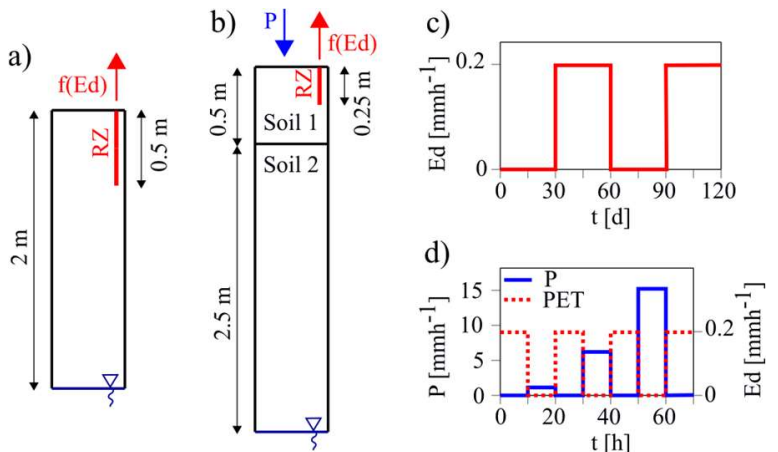

Figure 8: Definition of test cases dedicated to the evaluation of the unsaturated zone representation module. Geometry of test cases UZ1 (a) and UZ2 (b). Precipitation $(P)$ and evaporative demand $(E d)$ used in test cases UZ1 (c) and UZ2 (d). RZ = Root zone.

The test cases focus on single soil columns on which various rainfall and root water uptake conditions are applied to generate usual vertical water movements within common soils or infiltration devices. Columns are delimited in their lower boundary by a constant GW depth and are initially at a moisture content profile equilibrium state (i.e. $d \Psi=$ $d z)$.

\begin{tabular}{|c|c|c|c|c|c|c|c|c|c|c|c|c|}
\hline & \multicolumn{2}{|c|}{$I_{\text {surf }}\left[\mathrm{mmh}^{-1}\right]$} & \multicolumn{2}{|c|}{$F_{U Z-S Z}\left[\mathrm{mmh}^{-1}\right]$} & \multicolumn{2}{|c|}{$\operatorname{Tr}\left[\mathrm{mmh}^{-1}\right]$} & \multicolumn{2}{|c|}{$\theta_{U Z}[-]$} & \multicolumn{2}{|c|}{$\theta_{R Z}[-]$} & \multicolumn{2}{|c|}{$S_{\text {surf }}[\mathrm{mm}]$} \\
\hline & $\left|E_{t}\right|_{\text {mean }}$ & $R^{2}$ & $\left|E_{t}\right|_{\text {mean }}$ & $R^{2}$ & $\left|E_{t}\right|_{\text {mean }}$ & $R^{2}$ & $\left|E_{t}\right|_{\text {mean }}$ & $R^{2}$ & $\left|E_{t}\right|_{\text {mean }}$ & $R^{2}$ & $\left|E_{t}\right|_{\text {mean }}$ & $R^{2}$ \\
\hline UZ1 & - & - & 0.004 & 0.990 & 0.006 & 0.984 & 0.003 & 0.999 & 0.012 & 0.997 & - & - \\
\hline UZ2a & 0.131 & 0.966 & 0.211 & 0.950 & 0.002 & 0.963 & 0.001 & 0.999 & 0.013 & 0.908 & 0.699 & 0.997 \\
\hline $\mathrm{UZ2b}$ & 0.131 & 0.968 & 0.281 & 0.966 & 0.011 & 0.814 & 0.005 & 0.990 & 0.014 & 0.909 & 0.779 & 0.995 \\
\hline $\mathrm{UZ2c}$ & 0.038 & 0.993 & 0.017 & 0.790 & 0.000 & 0.999 & 0.001 & 0.999 & 0.009 & 0.942 & 3.492 & 0.999 \\
\hline
\end{tabular}

Table 6: Comparison results between the simulation outputs from the UZ module and the HYDRUS model for the test cases UZ1 and UZ2a to $c$.

\subsubsection{Test case UZ1: ability to simulate upward capillary rise from the water table}

The UZ1 test case is designed to evaluate the model's ability to simulate the upward water movement from the GW to supply the upper soil horizons during periods of low precipitation and high evaporation demand. It is based on a 2 $\mathrm{m}$ column of silt with a homogeneous root distribution over the first $50 \mathrm{~cm}$ (Figure 8a). Surface forcing consists of two 30 days periods of high evaporative demand without precipitation (Figure 8c).

The assessment is based on a comparison with results provided by the HYDRUS model solving the 1D Richards equations with the Brooks and Corey's model. The column is discretized into $0.5 \mathrm{~cm}$-thick elements. An atmospheric $\mathrm{BC}$ with a maximal pressure head of $1 \mathrm{~m}$ is assigned at the surface. An imposed pressure at $\mathrm{h}=0 \mathrm{~m}$ is assigned at the column bottom. The root water extraction is modelled using the Feddes model without compensation (Šimůnek and Hopmans, 2009). The evaluation focuses on the temporal evolution of the root water uptake (Tr), the exchanges between UZ and SZ $\left(F_{U Z-S Z}\right)$, the mean water content within the root zone $\left(\theta_{R Z}\right)$ and within the whole column $\left(\theta_{U Z}\right)$, considering the mean absolute error $\left|E_{t}\right|_{\text {moy }}$ (Eq. 24) and the determination criteria $R^{2}$ (Eq. 25). 


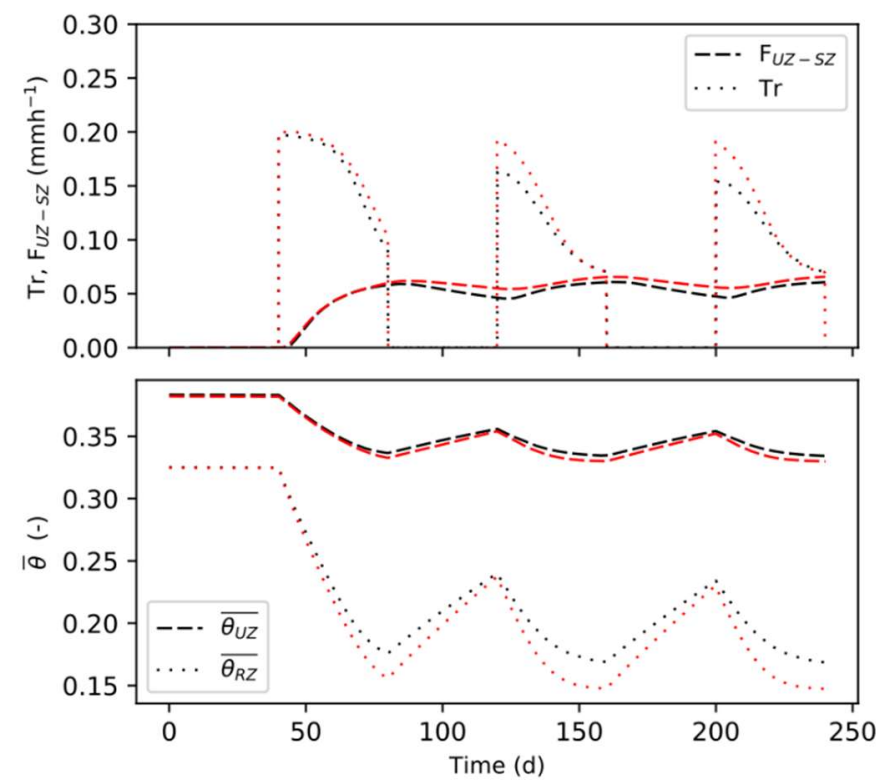

Figure 9: Simulation results of test case UZ1 provided by the unsaturated zone module (red lines) and HYDRUS $1 D$ (black lines): root water uptake (Tr), exchanges with groundwater $\left(F_{U Z-}\right.$ $S Z)$, mean water content $(\bar{\theta})$ in the root zone $\left(\overline{\theta_{R Z}}\right)$ and in the whole unsaturated zone $\left(\overline{\theta_{U Z}}\right)$.

Results related to this test case are shown in table 6 and Figure 9. It shows that the reservoir model slightly overestimates the root water uptake $(T r)$. This higher extraction of soil water directly results in lower average water content throughout the soil column $\left(\overline{\theta_{R Z}}\right.$ and $\left.\overline{\theta_{U Z}}\right)$ and, as a consequence, in a higher capillary rise from the GW $\left(F_{U Z-S Z}\right)$. The $\operatorname{Tr}$ overestimation is reinforced by the HYDRUS configuration (Feddes without compensation) which implies that the model does not seek to compensate for a decrease in root water uptake in stressed areas of the root profile by an increase in less stressed areas. Conversely, in the reservoir model, the root zone is entirely included in the first reservoir $(50 \mathrm{~cm})$. This implies an average value of the water content over the whole root zone. A reduction in the reservoir thickness then leads to a significant improvement in results (see section S3.2 of the supplementary material).

3.2.2. Test case UZ2: ability to simulate the evolution of storages and fluxes within homogeneous and layered unsaturated soils under various rainfall intensities 
Test case UZ2 aims to evaluate the model's accuracy in simulating the evolution of vertical fluxes and storage in homogeneous and layered soils subjected to periods of rainfall of various intensities and to redistribution periods with root extraction. The objective is to consider a set of soil and surface input combinations representative of common permeable areas and stormwater infiltration structures. Three sub-cases differing by soil characteristics are therefore considered. Test case UZ2a is based on a $3 \mathrm{~m}$ homogeneous column of silt. Test cases UZ2b and UZ2c cases rely on $3 \mathrm{~m}$ columns of layered soils designed to assess the module's ability to represent the influence of a different underlying soil layer. They are composed of a $0.5 \mathrm{~m}$ surface layer of silt on top of a $2.5 \mathrm{~m}$ layer of a material either more permeable (UZ2b: sand) or less permeable (UZ2c: clay) (Figure 8b). For the three sub-cases, roots are homogeneously distributed over the first $25 \mathrm{~cm}$. The rainfall inputs (Figure $8 \mathrm{~d}$ ), identical within the three sub-cases, are set to meet various possible cases of exceeding or not exceeding the infiltration capacity of the materials. They are interspersed with periods of moderate evaporative demand favouring the redistribution of water (Figure 8d).

The assessment is based on a comparison with results provided by the HYDRUS model configured identically to

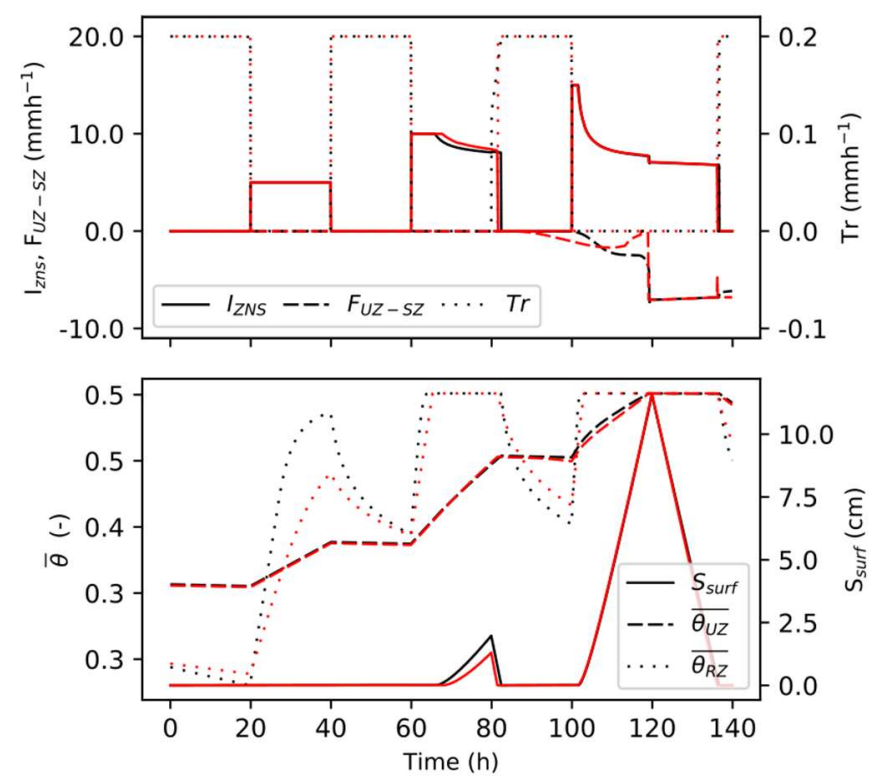

Figure 10: Simulation results of test case UZ2 a provided by the unsaturated zone module (red lines) and HYDRUS 1D (black lines): surface infiltration $\left(I_{\text {surf }}\right)$, exchanges with groundwater $\left(F_{U Z-S Z}\right)$, root water uptake $(T r)$, surface storage $\left(S_{\text {surf }}\right)$ and mean water content $(\bar{\theta})$ in the root zone $\left(\overline{\theta_{R Z}}\right)$ and in the whole unsaturated zone $\left.\overline{\left(\theta_{U Z}\right.}\right)$.

case UZ1 (except for the column extension and soil characteristics). The evaluation focuses on the temporal evolution of the surface infiltration $\left(I_{\text {sur }}\right)$, the root water uptake $(T r)$, the exchanges between UZ and SZ $\left(F_{U Z-S Z}\right)$, the surface storage $\left(S_{\text {surf }}\right)$, and the mean water content within the root zone $\left(\theta_{R Z}\right)$ and within the whole column $\left(\theta_{U Z}\right)$, considering the mean absolute error $\left|E_{t}\right|_{\text {mean }}$ (Eq. 24) and the determination criteria $R^{2}$ (Eq. 25). 
Results related to the test case UZ2a show that the model properly estimates rainfall infiltration $\left(I_{\text {surf }}\right)$ in a homogeneous soil (Table 6, Figure 10) using both the reservoir model (first rainfall pulse with $i_{\text {sup }}<K s$ ) and the Green-Ampt model (second and third pulses with $i_{s u p}>K s$ ). The latter provides better results when the inflow more distinctly exceeds the hydraulic saturation conductivity of the surface soil (the third pulse). The good matching of mean water contents $\left(\overline{\theta_{R Z}}\right.$ and $\left.\overline{\theta_{U Z}}\right)$ variations during and between rainfall inputs validates the coupling between the Green-Ampt model and the reservoir model. The root water extraction (Tr) is overall satisfactorily reproduced. By hypothesis, $\operatorname{Tr}$ is not computed in the reservoirs where the Green-Ampt computation occurs. This leads to the error visible at $\mathrm{t} \sim 80 \mathrm{~h}$. Exchanges with the SZ $\left(F_{U Z-S Z}\right)$ are overall less accurately reproduced. For $t<120 \mathrm{~h}$, they are computed by the reservoir model. The homogenization of incoming volumes over the lower reservoir thus leads to a smoother and earlier recharge ( $90 \mathrm{~h}<t<120 \mathrm{~h}$ - Figure 10). For $\mathrm{t} \sim 120 \mathrm{~h}$, the infiltration front computed by the Green-Ampt model enters the lowest reservoir. The reservoir model computation within this reservoir therefore stops and $F_{U Z \text {-SZ }}$ suddenly drops to zero until the infiltration front reaches the GW table ( $\mathrm{t} \sim 120 \mathrm{~h}$ - Figure 13). At $\mathrm{t} \sim 135$ $\mathrm{h}$, the Green-Ampt model computation stops. $F_{U Z-S Z}$ therefore drops during this time step before being calculated with the reservoir model at the next time step. A decrease in the reservoir thickness near the water table leads to a significant improvement in the estimation of these exchanges (see section S3.2 of the supplementary material).
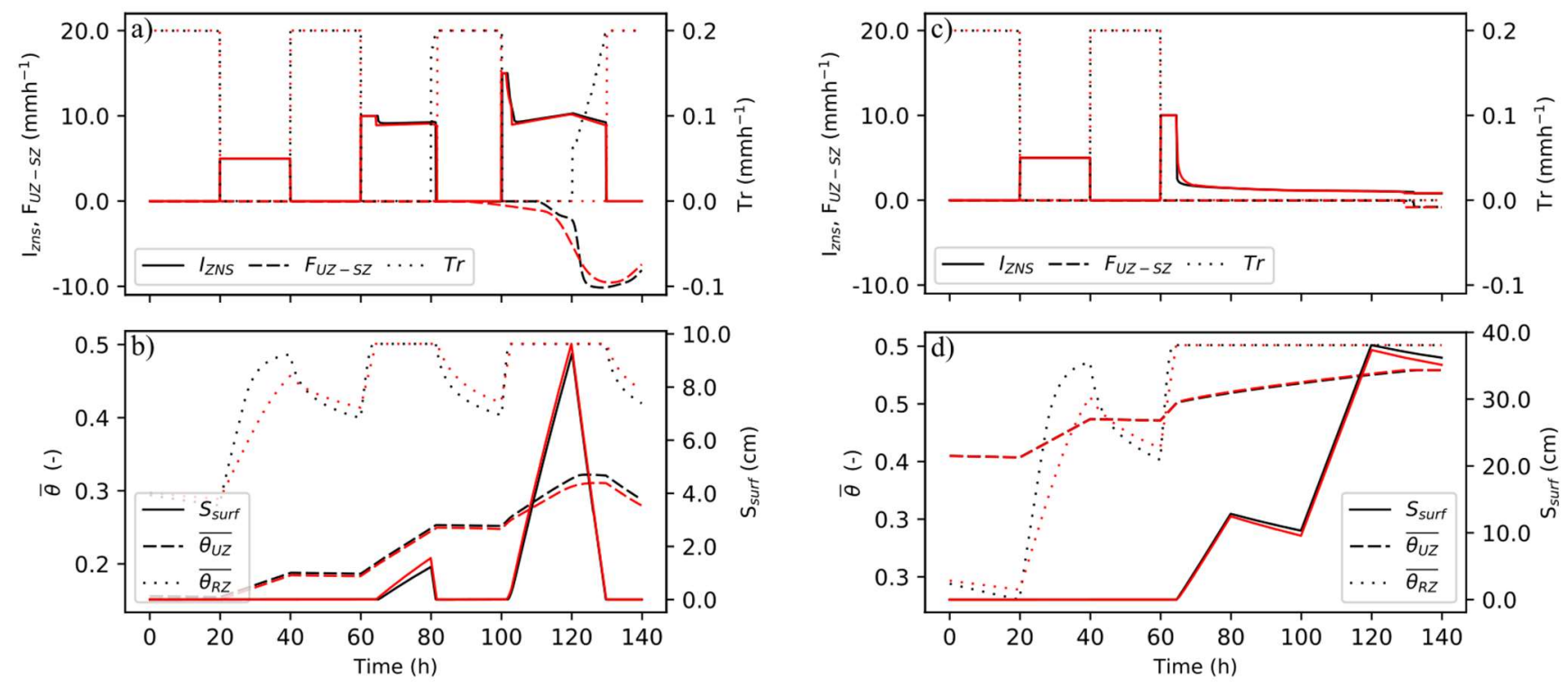

Figure 11: Simulation results of test cases UZ2b (figures a) and b)) and UZ2c (figures c) and d)) provided by the unsaturated zone module (red lines) and HYDRUS $1 D$ (black lines): surface infiltration $\left(I_{\text {surf }}\right)$, exchanges with groundwater $\left(F_{U Z-S Z}\right)$, root water uptake $(T r)$, surface storage $\left(S_{\text {surf }}\right)$ and mean water content $(\bar{\theta})$ in the root zone $\left(\overline{\theta_{R Z}}\right)$ and in the whole unsaturated zone $\left(\overline{\theta_{U Z}}\right)$.

The model satisfactorily reproduces the impact of a transition to a more permeable environment on the various UZ variables (case UZ2b - Table 6, Figure $11 \mathrm{a}$ and b). The Green-Ampt model slightly underestimates $I_{\text {surf }}$ when the infiltration front reaches the boundary between media $(65 \mathrm{~h}<\mathrm{t}<80 \mathrm{~h}$ and $105 \mathrm{~h}<\mathrm{t}<130 \mathrm{~h}$ - Figure 11a). It results in a slight overestimation of the surface ponding $\left(S_{\text {surf }}\right)$ (Table 6, Figure 11b). Not computing $\operatorname{Tr}$ within reservoirs where the Green-Ampt computation occurs results here in a significant underestimation of this flux $(\mathrm{t} \sim 80 \mathrm{~h}$ and $\mathrm{t} \sim$ $120 \mathrm{~h}$ - Figure 11a). The GW recharge $(t>90 \mathrm{~h})$ is here estimated by the reservoir model, which lead to similar conclusions as for the homogeneous soil (earlier and smoother recharge). 
The model also properly reproduces the influence of an underlying low permeable layer on the various fluxes and storages (case UZ2b - Table 66, Figure $11 \mathrm{c}$ and d). $I_{\text {surf }}$ and $S_{\text {surf }}$ are accurately reproduced. However, the GreenAmpt model slightly underestimates the time for the front to reach the water table ( $t>130 \mathrm{~h}$ - Figure $11 \mathrm{c})$. In contrast to the previous cases, a refinement of discretization does not correct this error (see section 3.2 of the supplementary material).

\subsection{Evaluation of the coupling}

Three test cases are dedicated to the evaluation of the coupling between UZ and SZ. They are simulated using the whole subsurface modelling approach described in section 2 using a constant time step of 6 minutes.
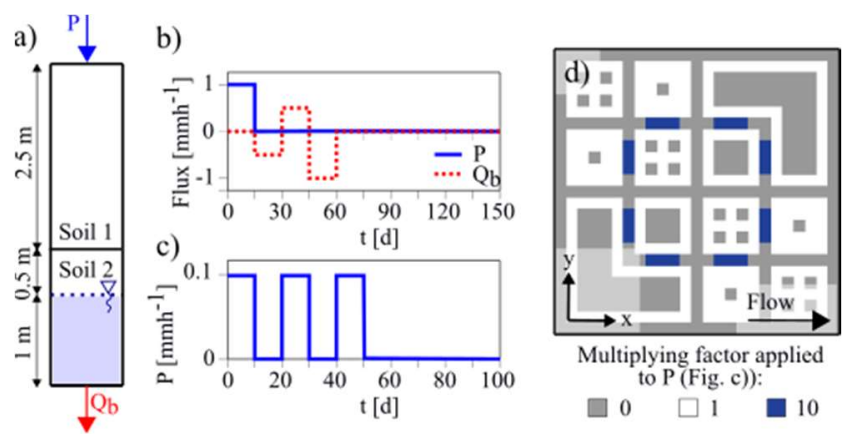

Figure 12: Definition of test cases dedicated to the evaluation of the UZ-SZ coupling. Geometry of the soil column used in the test case CO1 (a), atmospheric inputs used in test cases $\mathrm{CO} 1$ (b) and $\mathrm{CO} 2$ (c) and spatial distribution of surface inputs for the CO2b test case (d).

\subsubsection{Test case CO1: ability to simulate interactions between water table variation and unsaturated zone}

Test case $\mathrm{CO} 1$ is intended to assess interactions between GW and $\mathrm{UZ}$ during GW fluctuations. It focuses on a single $4 \mathrm{~m}$ column of soil (without lateral exchanges) subject to rainfall inputs and a SZ sink term (e.g. pumping well) (Table 7 and Figure 12). The column is initially at hydrostatic equilibrium (i.e. $d h=d z$ ) with a bottom boundary condition fixed at $h=1 \mathrm{~m}$ (i.e. the $\mathrm{GW}$ table is at a $3 \mathrm{~m}$ depth from the surface). The column is discretized into $0.5 \mathrm{~m}$ reservoirs. The minimum thickness of the lower reservoir is set at $d_{\min }=0.1 \mathrm{~m}$. Test case CO1 is divided into three sub-cases. Test case CO1a focuses on a homogeneous column of silt. Test cases CO1b and CO1c focuses on layered columns to assess the model's ability to reproduce the influence of material change (including the influence of the CF conceptualization presented in section 2.2.3) on groundwater level variations. Two configurations are considered: a more permeable soil above (CO1b: $2.5 \mathrm{~m}$ of silt over $1.5 \mathrm{~m}$ of sand) or a more permeable soil below (CO1c: $2.5 \mathrm{~m}$ of sand over $1.5 \mathrm{~m}$ of silt) (Tables 1 and Figure 12a).

The assessment is based on a comparison with results provided by the HYDRUS model solving the 1D Richards equations with the Brooks and Corey's model. The column is discretized into $0.5 \mathrm{~cm}$-thick elements. An atmospheric $\mathrm{BC}$ with a maximal pressure head of $1 \mathrm{~m}$ is assigned at the surface. A variable flow BC is assigned at the column bottom. The evaluation focuses on the temporal evolution of the water table elevation $\left(H_{t}\right)$ and the storage in the unsaturated zone $\left(S_{U Z}\right)$, considering the mean absolute error $\left|E_{t}\right|_{\text {mean }}$ (Eq. 24) and the determination criteria $R^{2}$ (Eq. 25). 


\begin{tabular}{|c|c|c|c|c|}
\cline { 2 - 5 } \multicolumn{1}{c|}{} & \multicolumn{2}{c|}{$H[\mathrm{~m}]$} & \multicolumn{2}{c|}{$S_{\text {zns }}[\mathrm{mm}]$} \\
\cline { 2 - 5 } \multicolumn{1}{c|}{} & $\left|E_{t}\right|_{\text {mean }}$ & $R^{2}$ & $\left|E_{t}\right|_{\text {mean }}$ & $R^{2}$ \\
\hline CO1a & 0.038 & 0.989 & 0.022 & 0.975 \\
\hline CO1b & 0.027 & 0.990 & 0.020 & 0.923 \\
\hline CO1c & 0.060 & 0.968 & 0.031 & 0.896 \\
\hline
\end{tabular}

Table 7: Comparison results between the simulation outputs from the UZ-SZ coupling and the HYDRUS model for the test cases COla to c.

Results related to test cases CO1a to c (Table 7 and Figure 13) show the model's ability to estimate the water table $(H)$ fluctuations and their influence on the unsaturated zone storage $\left(S_{U Z}\right)$. The system properly returns to its initial condition at the end of the simulation (the sum of the inflows/outflows being zero). Results also validate the conceptualization of the capillary fringe. In test cases $\mathrm{CO} 1 \mathrm{~b}$ and $\mathrm{CO} 1 \mathrm{c}$, the water table intersects the interface between mediums both during rise and fall and the two specific cases presented in section 2.2.3 are encountered. In both cases, the impact on both $H$ and $S_{U Z}$ is satisfactorily reproduced. However, the coarseness of the discretization leads to sharp variation in the water content when the SZ upper limit moves to a different reservoir. During following time steps, this results in adjustments of the water content by UZ-SZ exchanges to restore the equilibrium (Figure 13). A refinement of the discretization attenuates this effect but does not completely prevent it (see section S3.3 of the supplementary material).

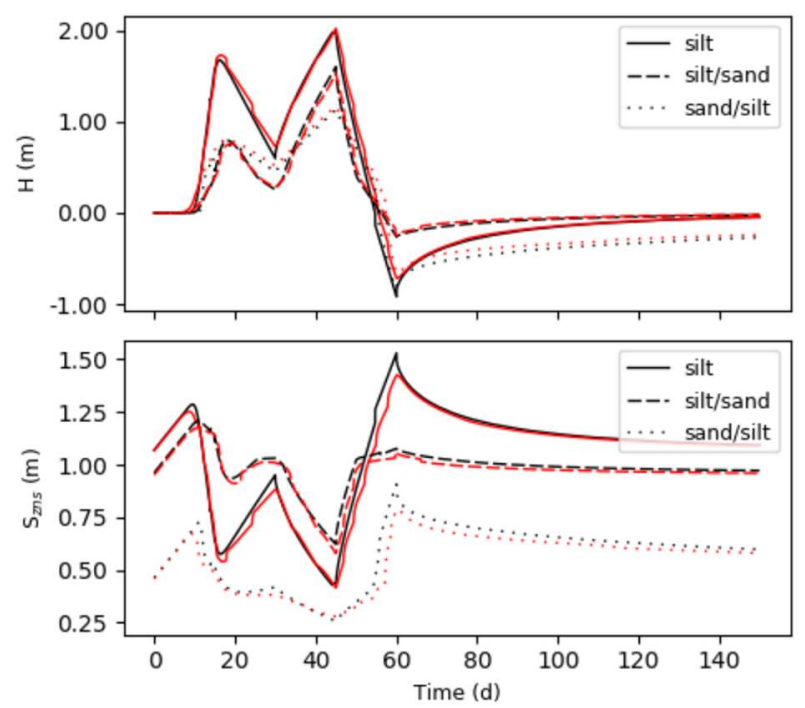

Figure 13: Simulation results of test cases COla to $c$ provided by the UZ-SZ coupling (red lines) and HYDRUS $1 D$ (black lines): water table elevation $(H)$ and storage in the unsaturated zone $\left(S_{U Z}\right)$.

\subsubsection{Test case CO2: ability to simulate the water table evolution under spatially homogeneous or heterogeneous upper input}

Test cases $\mathrm{CO} 2 \mathrm{a}$ and $\mathrm{CO} 3 \mathrm{~b}$ are designed to evaluate the coupling's accuracy in simulating the evolution of a water table in an unconfined aquifer subjected to a time varying surface input. The latter is either spatially homogeneous $(\mathrm{CO} 2 \mathrm{a})$ or heterogeneous $(\mathrm{CO} 2 \mathrm{~b})$ in order to reproduce a recharge similar to that occurring in a heterogeneous urban environment with infiltration devices.

The domain is a homogeneous medium composed of silt with an extension of $500 \mathrm{~m}$ x $500 \mathrm{~m}$ and a thickness of 20 $\mathrm{m}$. The slope of the top and bottom is $0.5 \%$. The GW level is fixed on the upstream and downstream boundaries at a 
depth of $3 \mathrm{~m}$ so that the surface of the GW table is parallel to the model's top and bottom at equilibrium state. In its initial state, the UZ-SZ system is in its moisture content profile equilibrium state. The reference rainfall pattern used as forcing is shown in Figure 12c. In test case CO2a, it is applied as is over the entire surface of the domain. In test case $\mathrm{CO} 2 \mathrm{~b}$, the surface is divided into 625 areas associated with three types of surface boundary conditions (Figure $12 \mathrm{~d})$, constructed by applying a multiplying factor $(0,1$ or 10$)$ to the reference rainfall intensity (Figure $12 \mathrm{c})$. The spatial discretization used for the simulation of both test cases corresponds to this division into 625 square cells. Each cell is then vertically discretized into $0.5 \mathrm{~m}$ reservoirs within the first $4 \mathrm{~m}$ at top of a reservoir of $16 \mathrm{~m}$.

The assessment is based on a comparison with results provided by the FEFLOW model solving the 3D Richards equations with the Brooks and Corey's model. The domain is horizontally discretized into elements of about $6 \mathrm{~m}^{2}$. Vertically, it is divided into layers of $0,05 \mathrm{~m}$ thick in the first meters to $1 \mathrm{~m}$ in the saturated part. The rainfall input is modelled by an inflow at the top of the domain. For the initial condition, a preliminary simulation without rainfall is performed until a steady state is reached. The evaluation focuses on:

- the spatial distribution of GW levels after 50 days $\left(H_{x y}-50 d\right), 100$ days $\left(H_{x y}-100 d\right)$ and 300 days $\left(H_{x y}-300 d\right)$, considering the mean absolute error $\left(\left|E_{x y}\right|_{\text {mean }}\right.$ (Eq. 22)) and the maximal absolute error ( $\left|E_{x y}\right|_{\max }$ (Eq. 23));

- the temporal evolution of GW levels at two points of the domain per test case, considering the mean absolute error $\left|E_{t}\right|_{\text {mean }}$ (Eq. 24) and the determination criteria $R^{2}$ (Eq. 25). For test case CO2a: the domain centre $\left(H_{t-\text { center }}\right)$ and $120 \mathrm{~m}$ downstream $\left(H_{t-120 m}\right)$. For test case $\mathrm{CO} 2 \mathrm{~b}$ : beneath an area of zero surface infiltration (domain center $-H_{t}$ - center) and beneath an area of concentrated surface infiltration (coordinates: $\mathrm{x}=310, \mathrm{y}=370-H_{t-B C 10}$ ).

\begin{tabular}{|c|c|c|c|c|c|c|c|c|c|c|c|c|}
\hline & \multicolumn{2}{|c|}{$H_{x y}-50 d[\mathrm{~m}]$} & \multicolumn{2}{|c|}{$H_{x y}-100 d[\mathrm{~m}]$} & \multicolumn{2}{|c|}{$H_{x y-300 d}[\mathrm{~m}]$} & \multicolumn{2}{|c|}{$H_{t-\text { center }}[\mathrm{m}]$} & \multicolumn{2}{|c|}{$H_{t-B C 10}[\mathrm{~m}]$} & \multicolumn{2}{|c|}{$H_{t-120 m}[\mathrm{~m}]$} \\
\hline & $\left|E_{x y}\right|_{\text {mean }}$ & $\left|E_{x y}\right|_{\max }$ & $\left|E_{x y}\right|_{\text {mean }}$ & $\left|E_{x y}\right|_{\max }$ & $\left|E_{x y}\right|_{\text {mean }}$ & $\left|E_{x y}\right|_{\max }$ & $\left|E_{t}\right|_{\text {mean }}$ & $R^{2}$ & $\left|E_{t}\right|_{\text {mean }}$ & $R^{2}$ & $\left|E_{t}\right|_{\text {mean }}$ & $R^{2}$ \\
\hline $\mathrm{CO} 2 \mathrm{a}$ & 0.011 & 0.013 & 0.007 & 0.011 & 0.005 & 0.008 & 0.008 & 0.998 & - & - & 0.009 & 0.993 \\
\hline $\mathrm{CO} 2 \mathrm{~b}$ & 0.018 & 0.246 & 0.008 & 0.081 & 0.003 & 0.006 & 0.004 & 0.999 & 0.021 & 0.990 & - & - \\
\hline
\end{tabular}

Table 8:Comparison results between the simulation outputs from the UZ-SZ coupling and the HYDRUS model for the test cases $\mathrm{CO} 2 a$ and $b$.

Results related to the test case CO2 (Table 8 and Figure 14 a and c) show that the fluctuations of a water table subject to a spatially homogeneous surface input are overall well reproduced. The model also satisfactorily reproduces GW level fluctuations with a heterogeneous surface forcing (test case CO2b - Table 8 and Figure $14 \mathrm{~b}$ and d). Below areas where the inflow is concentrated, the maximum elevation is slightly overestimated and the decrease in water table recession is sharper. (Figure 14d). As noticed in test case CO1, the water tale level may drop when the SZ upper limit moves to a different reservoir. This is especially noticeable during the lowering phase ( $\sim 90 \mathrm{~d}$ - Figure $14 \mathrm{~d})$. A refinement of the vertical discretization leads to smoothing the latter effect but only marginally influences overestimation of the peak elevation and of the recession rate (see section 3.3 of the supplementary material). 

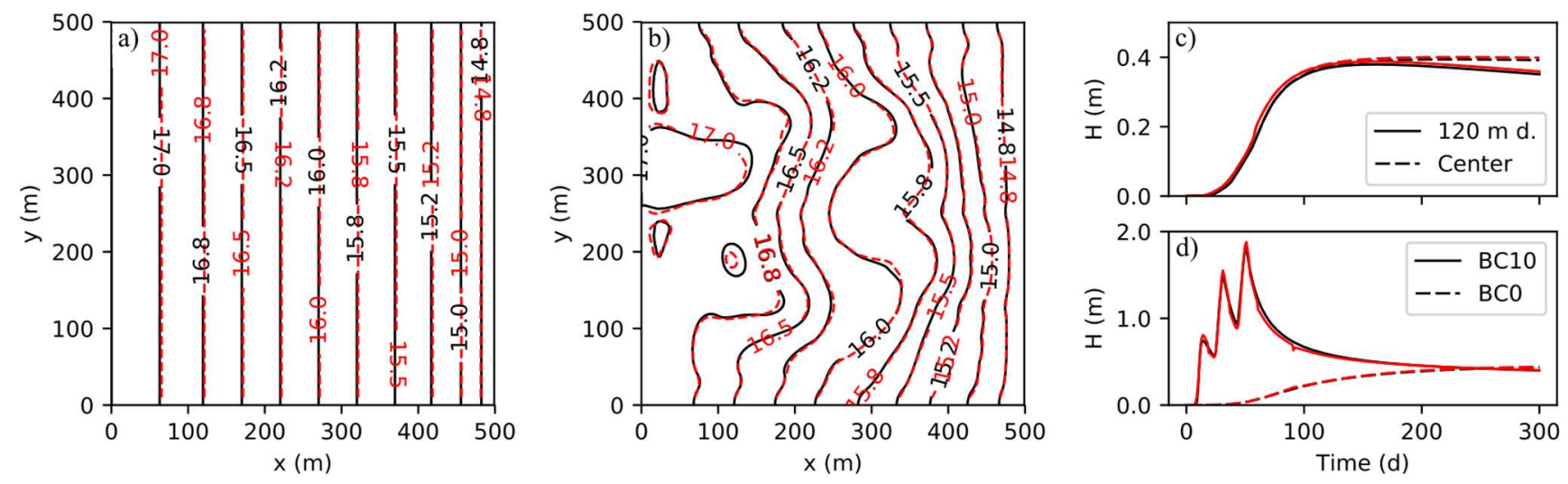

Figure 14: Groundwater levels computed by the UZ-SZ coupling (red lines) and FEFLOW for test cases CO2a and CO2b. a) Groundwater level distribution after 100 days for a spatially heterogeneous surface input (case CO2a). b) Groundwater level distribution after 100 days for a spatially heterogeneous surface input (case CO2b). c) Groundwater level evolution at the domain center and 120 downgradient for a homogeneous surface input (case CO2a). d) Groundwater level evolution beneath an area without inflow at top (BCO) and with a concentrated inflow at top (BC10) for a heterogeneous surface input (case CO2b).

\section{Integration within the URBS model and preliminary application}

This section presents the integration of the developed modules within the URBS model (sub-section 4.1) and a preliminary application of the model to a hypothetical yet realistic watershed (sub-section 4.2).

\subsection{Brief description of the URBS model and integration of the new modules}

The URBS model provides continuous simulations of the hydrological functioning of urbanized watersheds (Rodriguez et al., 2008). It is based on a watershed discretization into urban hydrological elements (UHE's), each composed of a cadastral parcel and half of the associated street section. This results in a highly irregular grid adapted to the structuring elements of the urban environment. On each UHE, fluxes and storages are computed by land use profile (natural, street, building). Natural and street profiles can be partially covered by trees to take into account their role in rain interception and evapotranspiration. Runoff volumes generated over the various profiles are routed either to the outlet via the hydrographic network composed by street segments and sewer pipes or to stormwater management devices (green roofs, reservoir pavements, infiltration devices).

The initial modelling of the underground compartment assumes a soil where the water flows are controlled by an exponential decrease in hydraulic conductivity with depth. The soil characteristics are homogeneous over the simulation domain. The unsaturated zone is modelled by a single reservoir fed by infiltration from the surface storage (at constant rate), emptied by evapotranspiration. The exchanges between the unsaturated zone and the saturated zone take into account both gravitational and diffusion fluxes. GW flows are computed at each interface between UHEs using a 2D Darcy computation without correction of the gradient computation method for irregular meshes. GW seepage into sewer pipes is considered by using an analytical formula derived from agricultural drainage.

For more details, the reader may refer to Rodriguez et al. (2008), Morena (2004) and Li (2015).

New modules introduced in section 2 are integrated into the URBS model as alternative modelling options. However, URBS specificities require coupling assumptions and intermediate calculation steps. First of all, the UZ flow 
computation by land use profile implies that each SZ computation cell could be associated with of up to three UZ soil columns, each characterized by its own water content profile and UZ-SZ exchange flow. UZ computation on each land use profile is then done using an identical GW level and the exchange flows with the SZ are averaged over the computation cell. The water content update at the end of the time step (section 2.3) is then carried out by land use profile. Figure 15 presents a conceptual representation of the partitioning of (sub)UHE by land-use profiles and of the flows calculated on each profile.

a)

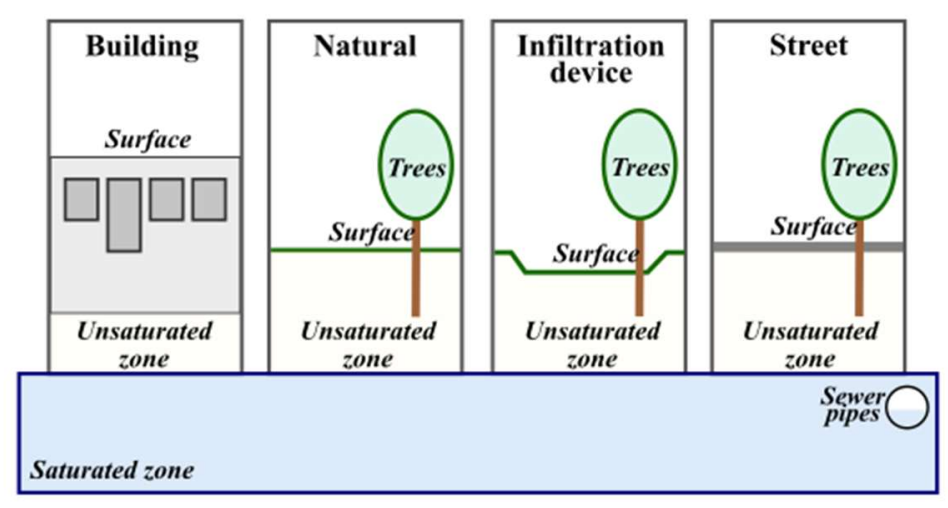

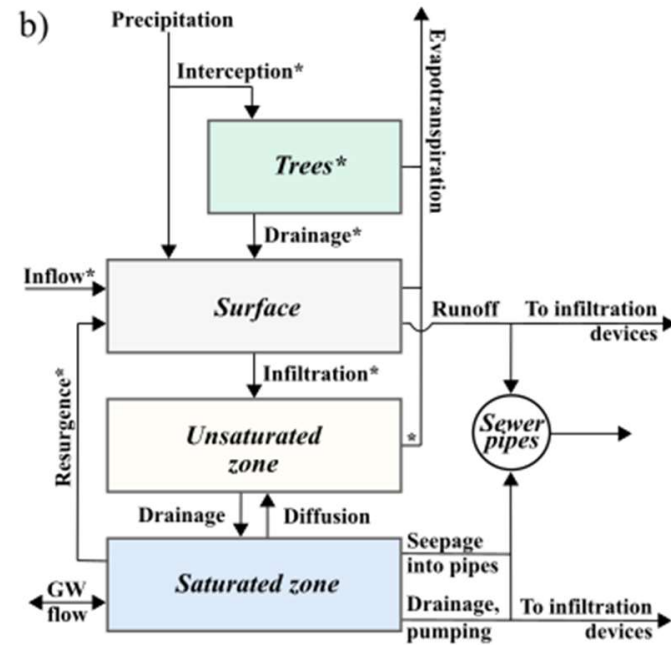

Figure 15: Schematization of the computation within the (sub)UHEs in the URBS model. a) Division of a (sub)UHE according to the land use profiles. b) Fluxes computed within a profile (* except for buildings).

Surface discretization into UHEs according to cadastral parcels is not optimal for the computation of underground flows 1) regarding the geometry of urban objects (e.g. infiltration devices, building basements), 2) regarding the characteristic scale of processes to be modelled (e.g. mounding effect) or 3) to ensure an accurate computation. Consequently, the possibility of using a refined underground mesh is added. In such case, each sub-UHE must be fully included in a single UHE to ensure proper code operation. Each sub-UHE can intersect several land use profiles. On each sub-UHE, subsurface flow computation is performed as described in section 2. Surface storage and runoff remain computed at the UHE scale. The infiltrated volume over each land use profile is then computed by averaging the contribution of each sub-UHE, weighted by the intersecting area of each profile. This sub level of discretization is defined in pre-processing and can be obtained for example using GIS tools to divide polygons (here the UHEs) into triangles. The application case presented in the following section provides an example of such a division of the UHEs into triangular sub-UHEs (Figure 16).

\subsection{Application to a hypothetical urban watershed}

This part presents an application of the resulting coupled model to a hypothetical yet realistic urban watershed concentrating various interactions between surface and sub-surface hydrology. It does not aim to validate the model but to highlight potential benefits of taking into account underground interactions when modelling urban water cycle in shallow GW environments.

\subsubsection{Description of the application case}

The watershed has an extension of $500 \mathrm{~m}$ x $500 \mathrm{~m}$, a constant thickness of $10 \mathrm{~m}$ and a uniform slope of $0.5 \%$. It is composed of 70 UHEs varying from $1100 \mathrm{~m}^{2}$ to $40000 \mathrm{~m}^{2}$ and spread over various areas representing either a dense 
urban environment, a commercial area, residential area and a natural area (Figure 16). From the bedrock to the surface, the soil is composed of a $9.3 \mathrm{~m}$ layer of loamy sand representing an aquifer formation, a $0.4 \mathrm{~m}$ layer of sand representing a reworked geological formation, and a $0.3 \mathrm{~m}$ layer of sandy clay loam (Table 1) representing the topsoil. Three buildings have basements set at $3 \mathrm{~m}$ (one underground level) with a hydraulic conductivity of $10^{-9} \mathrm{~ms}^{-1}$ and one of them is equipped with a drainage system (Figure 16). The sewer pipes (combined sewer systems) are located under the roads (Figure 16) at a depth of $2 \mathrm{~m}$. Their conductivity is considered homogeneous and equal to $G_{\text {sew }}=10^{-6} \mathrm{~ms}^{-1}$. Stormwater is managed by several infiltration devices (Figure 16) with a $20 \mathrm{~cm}$-depth, variable surfaces and where the soil is considered to be reworked (the two upper geological layers are replaced by a single layer of sand). In this simplified application, the runoff is assumed to be transferred immediately to the infiltration structures and/or the basin outlet without calculation of network flows. The GW level is fixed on the upstream and downstream boundaries (respectively left and right boundaries in Figure 16) at a 2m-depth so that the surface of the GW table is parallel to the model's top and bottom at equilibrium state without underground structures. A preliminary simulation without rainfall is done until steady state is reached in order to prevent artificial overestimation of the drained volumes. In its initial state, the UZ-SZ system is in its moisture content profile equilibrium state.

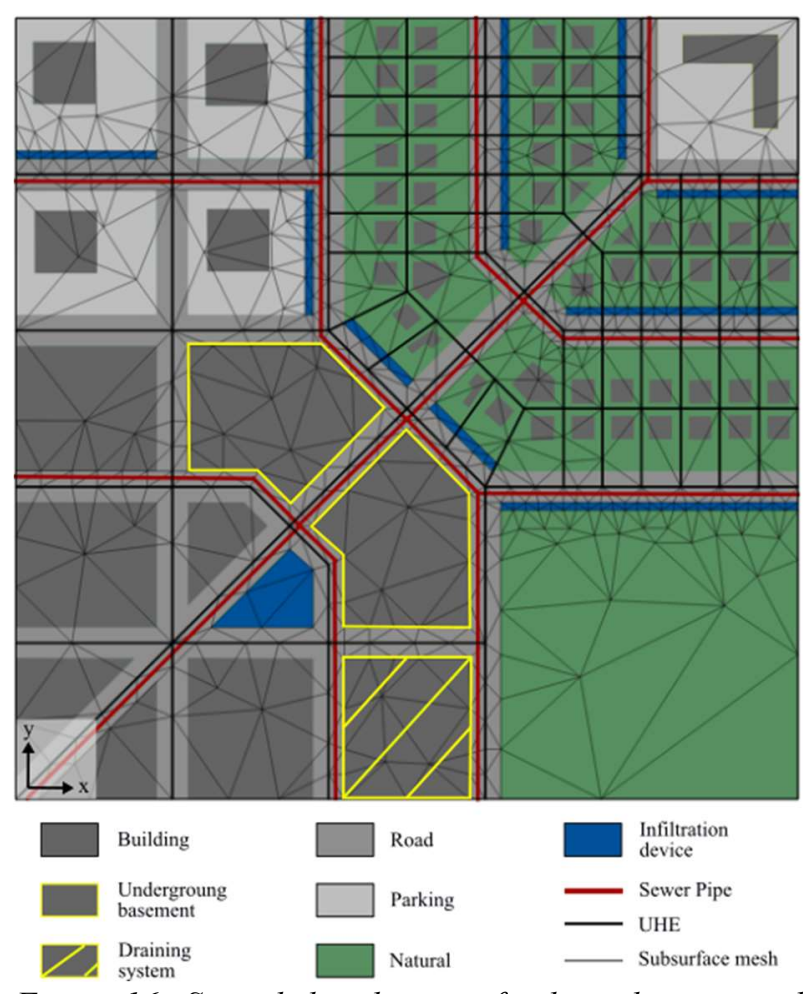

Figure 16: Spatial distribution of urban elements and subsurface mesh for the hypothetical application of the URBS model.

Five scenarios are built by successively adding components to the underground representation. The first scenario does not consider any interaction with the GW (the bedrock and the GW table are lowered down $20 \mathrm{~m}$ ). The second scenario focuses on GW interactions with surface without any underground structures. The third scenario includes sewer pipes but no building basements (with or without draining systems). The fourth scenario includes all the underground elements as detailed in the previous paragraph. The fifth scenario considers all underground elements but without infiltration devices in order to evaluate potential influence of these devices on the underground structures. The various scenarios are simulated over a continuous 1-year period using real rainfall records (6 min) and PET 
records (hourly, disaggregated from daily) from the Trappes station $\left(48,77^{\circ} \mathrm{N}-2,01{ }^{\circ} \mathrm{E}\right)$ for the year 2013 (Figure 17). The model is used with a constant 6 min time step. The subsurface mesh (Figure 16) is made of 1238 triangular cells with a refinement in the vicinity of the areas where sharp hydraulic gradients are expected (Figure 16).

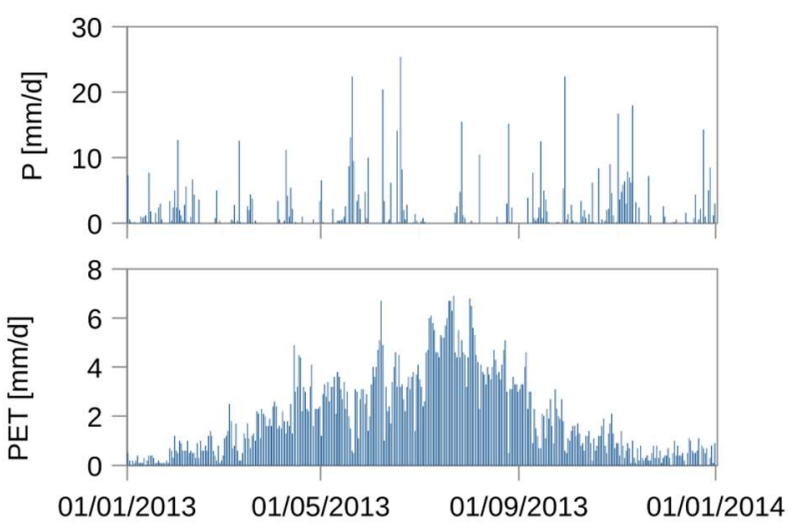

Figure 17: Rainfall $(P)$ and potential evapotranspiration (PET) records of the Trappes station for the year 2013

\subsubsection{Simulation results}

The simulation results related to the various scenarios are presented in Figure 18 and Table 9 and subsequently described.

\begin{tabular}{|c|c|c|c|c|c|}
\cline { 2 - 6 } \multicolumn{1}{c|}{} & $\begin{array}{c}\text { Without } \\
\text { interactions } \\
\text { with GW }\end{array}$ & GW only & $\begin{array}{c}\text { GW + Sewer } \\
\text { pipes }\end{array}$ & $\begin{array}{c}\text { GW + Sewer } \\
\text { pipes + building } \\
\text { basements }\end{array}$ & $\begin{array}{c}\text { Without } \\
\text { infiltration } \\
\text { devices }\end{array}$ \\
\hline Rainfall (mm) & 649 & 649 & 649 & 649 & 649 \\
\hline Infiltration (mm) & 526 & 450 & 458 & 472 & 202 \\
\hline Runoff (mm) & 11 & 85 & 76 & 64 & 335 \\
\hline Evaporation (mm) & 112 & 113 & 113 & 112 & 112 \\
\hline Transpiration (mm) & 143 & 165 & 160 & 156 & 151 \\
\hline Mean depth to GW (m) & - & 1.65 & 1.73 & 1.94 & 2.19 \\
\hline Infiltration into devices (mm) & 341 & 266 & 274 & 287 & - \\
\hline Mean depth to GW beneath devices (m) & - & 1.27 & 1.36 & 1.50 & 2.18 \\
\hline GW drainage by sewer pipes (mm) & - & - & 85 & 51 & 0 \\
\hline GW drainage by basements (mm) & - & - & - & 66 & 33 \\
\hline
\end{tabular}

Table 9: Simulation results of the various scenarios. Variables are calculated over the whole simulation and modelling domain. Results related to the first scenario show that when interactions with GW are neglected (scenario 1), almost all stormwater volumes conveyed to infiltration devices infiltrates. The comparison with the second scenario highlights the significant influence of considering interactions between $\mathrm{GW}$ and infiltration devices on simulations results. This directly results in a significant drop in infiltration within the structures and, consequently, in an increase in runoff. In addition, taking into account the influence of capillary rise from the shallow GW leads here to a higher estimation of the transpiration.

The inclusion of sewer pipes (scenario 3) leads to a slight decrease in the simulated rise of the water table, both overall and in the mounding beneath infiltration devices (Table 9, Figure 18). The interactions between GW and surface are consequently reduced, and the simulation results present 1) an increase of the infiltration volumes in the infiltration devices and 2) a decrease of the evapotranspiration compared to the second scenario (GW only). 
The inclusion of all underground structures (scenario 4) leads to similar, but amplified, conclusions. This is mainly due to the high GW level reduction resulting from the draining system equipping the building basement which further reduces interactions between GW and surface compartment. Comparison of GW levels at the end of the simulation (Figure 18a) shows that this effect is locally more noticeable, especially for the infiltration device located upstream of the drainage system. This figure also shows that the draining system is a major outlet for the area and largely captures the water infiltrated into the upstream infiltration device. It strongly modifies local flow directions which leads, among others, to disruption of local exchanges between the water table and the downstream limit (which could represent a watercourse, for example). Neglecting such structures is therefore likely to bias the results when assessing the impact of infiltration strategies on runoff volumes, GW levels and base flow of neighbouring watercourses.
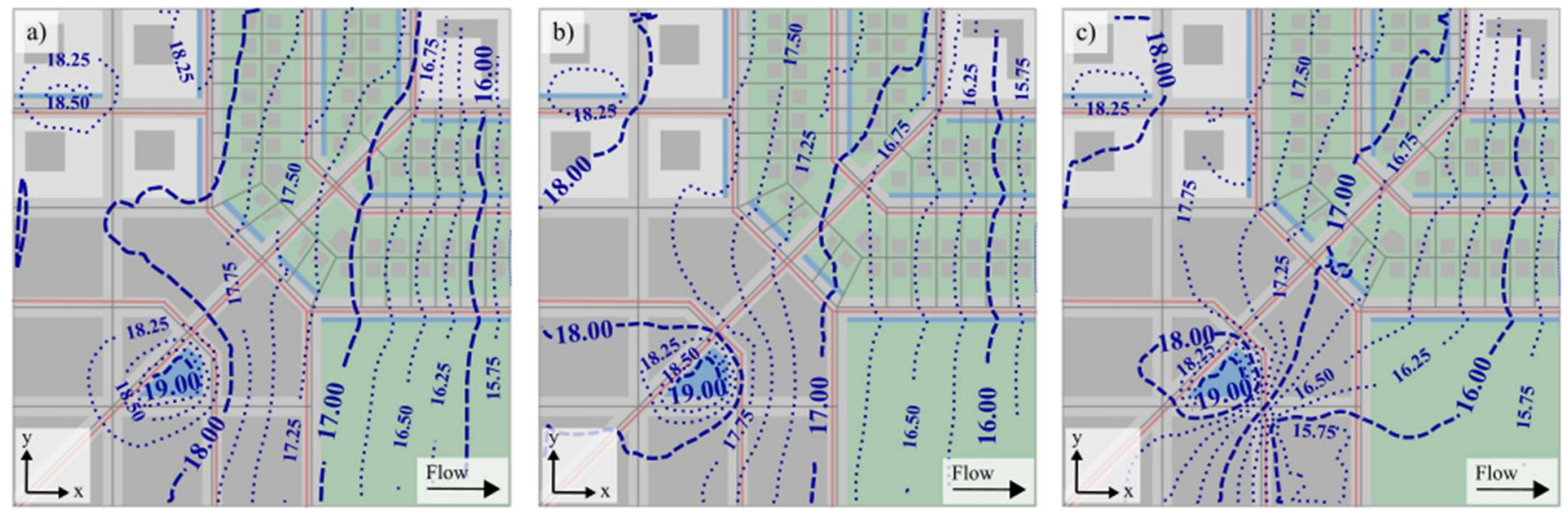

Figure 18: Hydraulic head isolines at the end of the simulation $(m)$ for scenarios without any underground structures $(a)$, with sewer pipes only (b) and with all underground structures (c).

Taking into account pipes and underground structures equipped with draining systems also makes it possible to estimate the extent to which the infiltration devices will increase the infiltration of GW returning to the sewer system by voluntary (draining system) and involuntary (pipes) drainage. For example, comparison between scenario 4 and 5 (without infiltration devices) shows that the implementation of infiltration devices leads to a 3.5 -fold increase in the GW volumes returning to the sewer system by drainage, difference which represents $29 \%$ of the volumes infiltrated into the infiltration devices.

\section{Discussion}

\subsection{Positioning and novelty of the modelling approach}

The modules developed in this study satisfactorily reproduce various processes and interactions commonly neglected in urban hydrological models (e.g. SWMM, URBS, WEP) although likely to significantly influence the urban water cycle in shallow groundwater environments. For instance, the unsaturated zone flow calculation module takes into account the influence of vertical soil heterogeneity and of capillary upwelling from the water table on the various related fluxes (e.g. infiltration and runoff formation, evapotranspiration, GW recharge or GW drainage to satisfy evaporative demand in dry periods). The GW flow calculation module allows the simulation of local GW fluctuations, for instance beneath stormwater infiltration devices, while taking into account lateral heterogeneities of the medium and various underground structures. It allows the estimation of groundwater volumes drained intentionally (pumping, drainage systems equipping underground structures) or not (e.g. seepage into sewer pipes). It is therefore possible to estimate the influence of these structures on the underground water storage and additional volumes to be managed 
by the sewerage system. Using irregular computation cells allows mesh adjustments to fit to urban objects geometry and potential refinements for a more precise estimation of local GW fluctuations and of the related interactions with the surface or underground structures. Furthermore, the coupling procedure between these modules takes into account the dynamic feedbacks between surface and underground compartments.

Although the modelling approach is relatively straightforward, the evaluation of the modules show that they provide results of satisfactory accuracy regarding 1) the objectives assigned to the inclusion of the underground compartment in urban hydrological models and 2) the high uncertainties regarding the underground compartment composition. They also ensure the water balance. The maximum water budget error for all simulations is reached in scenario 3 of the URBS model application case. The total error over one year of simulation is then below $0.001 \mathrm{~m}^{3}$ (about $5.10^{-7} \%$ of rain volumes).

The integration of the developed modules within the URBS model and its application to a hypothetical urban area illustrate the relevance of such developments to extend the applicability of an existing urban hydrological model in shallow GW environments. This allows the exploitation of existing model capabilities regarding the modelling of the surface hydrology of urbanized environments (e.g. runoff generation on impermeable and permeable surfaces, decentralised/centralised runoff management following complex water paths, transpiration by vegetation) while taking into account the specificities of these contexts. The final model can for example handle i) the influence of groundwater fluctuations on the infiltration capacity within permeable areas and stormwater infiltration devices or on transpiration by vegetation, ii) localized groundwater resurgences and their fate in the urban environment or iii) the influence of underground structures on groundwater storage and the fate of drained groundwater in the urban drainage system. The inclusion of these various components and dynamic feedbacks in an urban hydrological model is relatively novel. The level of detail in the description of the urban environment and hydrological processes makes this model suitable for studies at intermediate scales, typically from the city district to small urbanized catchment (a few $\mathrm{km} 2$ ). The integration of these new features as optional modules has the advantage of providing a single tool that can be easily adapted to the modelling context and objectives. Furthermore, the relative simplicity of the additional modules maintains fairly low computation times that remain compatible with sensitivity studies or multi-scenario modelling. It also allows a rather straightforward implementation in existing code. The open-source modules developed in this study may hence be used or adapted to extend in a similar way the applicability of other hydrological models for shallow GW contexts.

The modules developed in this study are not intended to be a substitute for a groundwater flow calculation system. As soon as the objectives imply a more accurate GW flow modelling, it is necessary to use a coupling with a hydrogeological model (e.g. MODFLOW, FEFLOW) or an integrated model dedicated to the natural environment (e.g. MIKE SHE, GSFLOW). Their implementation in the URBS model nevertheless provides a complementary tool allowing for example1) a rapid assessment of the relative influence of the various processes and interactions involved,

2) to identify where physically based groundwater models may be needed and 3) to perform multi-scenario modelling to handle the high uncertainties regarding the composition of the subsurface compartment (Clark et al., 2011).

\subsection{Limitations and needs for further developments}




\subsubsection{Spatio-temporal discretization and computation method}

The developed modules assume a single fixed time step (i.e. identical for each module and during the whole simulation) which highly facilitates the management of dynamic interactions between the various model components. However, the time step required for surface or UZ flow calculations is often unnecessarily fine for GW flow computation. The use of a module-specific time step does, however, introduce further questions on the maintenance of balances and communications between modules (Beegum et al., 2018; Branger et al., 2010).

Both SZ and UZ modules rely on a sequential computation of flow between the computing units, on the basis of hydraulic heads (SZ) or capillary pressures (UZ) at the previous time step. It distinguishes them from true hydrogeological models based on a numeric resolution, at each time step, of the matrix system linking all the calculation units. This method (combined with a fixed time step) limits the use of fine mesh, the minimum size of the elements depending on the soil characteristics. Below this value, the calculation may be unstable (see section 3 of the supplementary material). However, urban hydrological modelling usually requires few minutes time step to describe surface hydrological processes. Such time steps alleviate these restrictions and allows a relatively stable resolution as shown by the various test cases. Special attention must nevertheless be paid to discretization if larger time steps are used or if highly permeable soils are considered. The use of a variable time step for these modules (allowing, for example, a division of the time step for particular units) would make it possible to, at least partially, solve this issue. However, further development of the model should focus on the introduction of matrix resolutions for both UZ and SZ equations to extend the range of applicability of the model.

\subsubsection{Modelled processes}

Although the approach satisfactorily simulates subsurface flows, it suffers from various limitations that could restrict its scope of application but may be partially addressed in the future. First of all, the UZ model only considers single porosity media and further development should be carried out to allow for macropore flows, which can significantly influence UZ functioning and infiltration processes (Beven, 1982). Simple approaches such as those used in the MIKE-SHE model (DHI, 2017) seem to be adapted to the level of complexity of the module and the level of knowledge of the macropore distribution. Similarly, the GW flow calculation module cannot model the influence of double porosity (matrix and cracks) or horizontal anisotropy of the hydraulic conductivity in the aquifer. For the latter case, a minor modification of the calculation presented in part 2.1 could be considered, following for example the approach presented in (De Marsily, 1981). Anyway, the approach remains limited by the 2D assumption of a negligible vertical component of the hydraulic gradient. It may thus provide erroneous results when this assumption is not valid, for example in case of vertical anisotropy of permeability. Similarly, the UZ modelling method is simpler but remain less reliable and accurate than models solving the Richards 1D equations. However, the latter remain associated with a high computation time and potential convergence issues. Ross' approach (Ross, 2003) seems from this point of view to be an interesting alternative to the usual methods of solving the Richards equation.

The modelling of GW infiltration in sewer pipes is quite elementary. First of all, it assumes a homogeneous infiltration over the pipe length in a cell, whereas this infiltration is actually due to punctual defects (cracks, joints, ...). However, due to the low level of knowledge of the spatial distribution of these defects, this homogeneous infiltration assumption is reasonable. Furthermore, such description would allow the use of distributed value for the parameters controlling GW-sewer interactions if the conditions of sewer pipes were known. A second limitation of the module is that it does 
not consider the head in the pipes for the computation. Further developments should introduce this functionality to represent more realistically interactions between GW and pipes.

Finally, the vegetation depiction is relatively simplified. It would in particular be relevant to introduce the possibility to vary vegetation characteristics throughout the year and to take into account compensation processes in the root zone.

\section{Conclusion}

This paper details the development, the evaluation and the integration within the urban hydrological model URBS of a set of modules designed to depict the urban underground compartment in shallow groundwater contexts. The unsaturated flow computation is based on a coupling between a reservoir model and a Green-Ampt model. It allows taking into account the influence of a shallow water table on infiltration and evapotranspiration processes, in homogeneous or stratified soils. The modelling of the saturated zone is based on a 2D groundwater flow computation allowing 1) the use of irregular meshes adapted to the geometry of urban components and 2) the simulation of interactions between groundwater and various underground structures: sewer pipes, wells, underground constructions (basements, car parks, etc.) with or without draining systems The evaluation of the modules by comparison with reference models (HYDRUS and FEFLOW) shows their ability to efficiently reproduce the processes and interactions of interest.

The new modules are integrated within the URBS model through an approach allowing dynamic feedbacks between the various components. It provides an original framework for the assessment of the impacts of urban development or stormwater management strategies in shallow groundwater contexts. Its application to a hypothetical yet realistic urban area illustrates the benefits of such integration to extend the applicability of an existing urban hydrogeological model to such contexts. The approach presented in this paper could be adapted to complement existing modelling frameworks to provide a more realistic description of the hydrological functioning of urbanized watersheds in shallow groundwater contexts.

\section{Acknowledgments}

This study was carried out under the OPUR program and supported by the French Ministry for the Ecological and Inclusive Transition and the French National Institute for Agriculture, Food, and Environment. The study also contributes to the research conducted within OTHU (Field Observatory in Urban Hydrology) and the ONEVU (Nantes Urban Environment Observatory).

The authors would like to thank Marie Laure-Mosini for her useful contribution to the development of the URBS software.

The authors acknowledge DHI for the sponsored FEFLOW license.

\section{Author contributions}

W.P., J.S., F.R. and I.B. designed the research; W.P. coded the model and performed the simulations; J.S., F.R. and I.B. contributed to the definition of the model and the methods. W.P., wrote a first version of the paper that was revised by J.S., F.R. and I.B. 


\section{References}

Attard, G., Rossier, Y., Winiarski, T., Cuvillier, L., Eisenlohr, L., 2016a. Deterministic modelling of the cumulative impacts of underground structures on urban groundwater flow and the definition of a potential state of urban groundwater flow: example of Lyon, France. Hydrogeol J 24, 1213-1229. https://doi.org/10.1007/s10040-016-1385-z

Attard, G., Winiarski, T., Rossier, Y., Eisenlohr, L., 2016b. Review: Impact of underground structures on the flow of urban groundwater. Hydrogeol J 24, 5-19. https://doi.org/10.1007/s10040-015-1317-3

Beegum, S., Šimůnek, J., Szymkiewicz, A., Sudheer, K.P., Nambi, I.M., 2018. Updating the Coupling Algorithm between HYDRUS and MODFLOW in the HYDRUS Package for MODFLOW. Vadose Zone Journal 17, 180034. https://doi.org/10.2136/vzj2018.02.0034

Beven, K., 1982. On subsurface stormflow: an analysis of response times. Hydrological Sciences Journal $27,505-521$. https://doi.org/10.1080/02626668209491129

Bhaskar, A.S., Beesley, L., Burns, M.J., Fletcher, T.D., Hamel, P., Oldham, C.E., Roy, A.H., 2016. Will it rise or will it fall? Managing the complex effects of urbanization on base flow. Freshwater Science 35, $293-310$. https://doi.org/10.1086/685084

Bhaskar, A.S., Hogan, D.M., Nimmo, J.R., Perkins, K.S., 2018. Groundwater recharge amidst focused stormwater infiltration. Hydrological Processes 32, 2058-2068. https://doi.org/10.1002/hyp.13137

Bonneau, J., Fletcher, T.D., Costelloe, J.F., Poelsma, P.J., James, R.B., Burns, M.J., 2018. Where does infiltrated stormwater go? Interactions with vegetation and subsurface anthropogenic features. Journal of Hydrology 567, 121-132. https://doi.org/10.1016/j.jhydrol.2018.10.006

Bouwer, H., 2002. Artificial recharge of groundwater: hydrogeology and engineering. Hydrogeology Journal 10, $121-142$. https://doi.org/10.1007/s10040-001-0182-4

Branger, F., Braud, I., Debionne, S., Viallet, P., Dehotin, J., Henine, H., Nedelec, Y., Anquetin, S., 2010. Towards multi-scale integrated hydrological models using the LIQUID ${ }^{\circledR}$ framework. Overview of the concepts and first application examples. Environmental Modelling \& Software 25, 1672-1681. https://doi.org/10.1016/j.envsoft.2010.06.005

Brooks, R.H., Corey, A.T., 1964. Hydraulic properties of porous media. Hydrology Paper No. 3. Colorado State Univ., Fort Collins, Colorado.

Clark, M.P., Kavetski, D., Fenicia, F., 2011. Pursuing the method of multiple working hypotheses for hydrological modeling: HYPOTHESIS TESTING IN HYDROLOGY. Water Resources Research 47. https://doi.org/10.1029/2010WR009827

De Marsily, G., 1981. Hydrogéologie quantitative, Collection Sciences de la terre. Masson, Paris ; New York.

DHI, 2017. MIKE SHE User Manual—Volume 2: Reference.

Diersch, H.-J.G., 2014. FEFLOW: finite element modeling of flow, mass and heat transport in porous and fractured media. Springer, Berlin.

Feddes, R.A., Kowalik, P.J., Zaradny, H., 1978. Simulation of field water use and crop yield, Simulation monographs. Centre for Agricultural Publishing and Documentation, Wageningen.

Fletcher, T.D., Andrieu, H., Hamel, P., 2013. Understanding, management and modelling of urban hydrology and its consequences for receiving waters: A state of the art. Advances in Water Resources 51, 261-279. https://doi.org/10.1016/j.advwatres.2012.09.001

Göbel, P., Stubbe, H., Weinert, M., Zimmermann, J., Fach, S., Dierkes, C., Kories, H., Messer, J., Mertsch, V., Geiger, W.F., Coldewey, W.G., 2004. Near-natural stormwater management and its effects on the water budget and groundwater surface in urban areas taking account of the hydrogeological conditions. Journal of Hydrology 299, $267-283$. https://doi.org/10.1016/j.jhydrol.2004.08.013

Hamel, P., Fletcher, T.D., 2014. Modelling the impact of stormwater source control infiltration techniques on catchment baseflow. Hydrol. Process. 28, 5817-5831. https://doi.org/10.1002/hyp.10069

Jia, Y., Ni, G., Kawahara, Y., Suetsugi, T., 2001. Development of WEP model and its application to an urban watershed. Hydrological Processes 15, 2175-2194. https://doi.org/10.1002/hyp.275

Jia, Y., Tamai, N., 1997. Modeling Infiltration into a Multi-layered Soil during an Unsteady Rain. PROCEEDINGS OF HYDRAULIC ENGINEERING 41, 31-36. https://doi.org/10.2208/prohe.41.31

Kidmose, J., Troldborg, L., Refsgaard, J.C., Bischoff, N., 2015. Coupling of a distributed hydrological model with an urban storm water model for impact analysis of forced infiltration. Journal of Hydrology 525, 506-520. https://doi.org/10.1016/j.jhydrol.2015.04.007

Li, Y., 2015. Modeling of hydrological processes of an urban catchment. Study of a saturated soil flow module and application to an urban development zone of the future Paris-Saclay University. Université Nantes Angers Le Mans.

Locatelli, L., Mark, O., Mikkelsen, P.S., Arnbjerg-Nielsen, K., Deletic, A., Roldin, M., Binning, P.J., 2017. Hydrologic impact of urbanization with extensive stormwater infiltration. Journal of Hydrology 544, 524-537. https://doi.org/10.1016/j.jhydrol.2016.11.030

Morena, F., 2004. Modélisation hydrologique distribuée en milieu urbanisé.

Morris, D.A., Johnson, A.I., 1967. Summary of Hydrologic and Physical Properties of Rock and Soil Materials, as Analyzed by the Hydrologic Laboratory of the U.S. Geological Survey 1848-60. Geological Survey Water-Supply Paper $1839-\mathrm{D} 46$.

Rodriguez, F., Andrieu, H., Morena, F., 2008. A distributed hydrological model for urbanized areas - Model development and application to case studies. Journal of Hydrology 351, 268-287. https://doi.org/10.1016/j.jhydrol.2007.12.007

Ross, P.J., 2003. Modeling Soil Water and Solute Transport-Fast, Simplified Numerical Solutions. Agronomy Journal $95,1352$. https://doi.org/10.2134/agronj2003.1352

Rossman, L.A., 2016. Storm Water Management Model Reference Manual, Volume I - Hydrology (Revised) 233. 
Salvadore, E., Bronders, J., Batelaan, O., 2015. Hydrological modelling of urbanized catchments: A review and future directions. Journal of Hydrology 529, 62-81. https://doi.org/10.1016/j.jhydrol.2015.06.028

Šimůnek, J., Hopmans, J.W., 2009. Modeling compensated root water and nutrient uptake. Ecological Modelling $220,505-521$. https://doi.org/10.1016/j.ecolmodel.2008.11.004

Šimůnek, J., Van Genucthen, M.T., Šejna, M., 2005. The HYDRUS-1D software package for simulating the one-dimensional movement of water, heat and multiple solutes in variably-saturated media, version 3.0.

United Nations, 2014. World urbanization prospects: the 2014 revision; highlights. United Nations, New York.

Zha, Y., Yang, J., Zeng, J., Tso, C.M., Zeng, W., Shi, L., 2019. Review of numerical solution of Richardson-Richards equation for variably saturated flow in soils. WIREs Water 6. https://doi.org/10.1002/wat2.1364

Zhang, K., Chui, T.F.M., 2020. Assessing the impact of spatial allocation of bioretention cells on shallow groundwater - An integrated surface-subsurface catchment-scale analysis with SWMM-MODFLOW. Journal of Hydrology 586, 124910. https://doi.org/10.1016/j.jhydrol.2020.124910 